Terradillos Basoco, Juan M, "Apuntes políticocriminales en torno a la corrupción pública como delincuencia socioeconómica organizada. El caso español", Nuevo Foro Penal, 93, (2019).

\title{
Apuntes político-criminales en torno a la corrupción pública como delincuencia socioeconómica organizada. El caso español*
}

\author{
Political-criminal notes on public corruption as organized \\ socioeconomic crime. The spanish case
}

Juan M. TerRadillos Basoco**

Fecha de recepción: 12/07/2019 - Fecha de aceptación: 23/09/2019

DOI: 10.17230/nfp.15.93.1

\section{Resumen}

La corrupción pública, sobre todo en forma de "gran corrupción", participa de los caracteres de la criminalidad económica organizada. Por tanto, la política criminal frente a los delitos de corrupción debe inicialmente promover las reformas de derecho penal y procesal tendentes a prevenir las conductas de funcionarios corruptos y de particulares corruptores. Pero debe también implementar políticas de amplio alcance tendentes a neutralizar los factores criminógenos (pro-corrupción) integrados en el sistema de economía globalizada.

\footnotetext{
* El texto parte, con las necesarias adaptaciones, de la conferencia pronunciada en el Seminario Hispano-Italiano "Derecho Penal Económico y Corrupción", organizado por la Red temática "Consecuencias de la Gran Recesión de 2008 en el Derecho penal económico: oportunidad y desafío" (DER2017-90667-REDT), y por el Grupo de Investigación "Derecho penal y sistema económico" (PAl, SEJ-378). Facultad de Derecho, Universidad de Cádiz (España), 27/28.03.2019.

* Juan M. Terradillos Basoco. Profesor emérito. Catedrático de Derecho Penal. Universidad de Cádiz (España). Director del Grupo de Investigación PAI2000-SEJ-378, "Sistema penal y actividad económica". Contacto: juan.terradillos@uca.es
} 
12 Apuntes político-criminales en torno a la corrupción pública como delincuencia socioeconómica organizada.

El caso español - Juan M. Terradillos Basoco

\section{Abstract}

Politic corruption, overall the one known as "grand corruption", shares characteristics with organized economic crime. Thus, criminal policy against corruption crime must promote, initially, changes on criminal and procedural law in order to prevent behaviours from corrupt officials and corrupting individuals. But it also must introduce wide-ranging policies to counteract factors that encourage crime (pro-corruption) which are integrated into the globalized economic system.

\section{Palabras clave}

Cooperación internacional, corrupción política, criminalidad económica, decomiso, derecho penal, fraude fiscal, globalización, independencia judicial, procedimiento penal, transparencia..

\section{Keywords}

International cooperation, politic corruption, economic crime, confiscation, criminal law, tax fraud, globalization, judicial independence, criminal procedure, transparency.

\section{Sumario}

1. Planteamiento. 2. Corrupción pública y delincuencia socioeconómica. 3. Apuntes político-criminales. 3.1. Derecho penal sustantivo. 3.1.1. Delitos. 3.1.2. Sanciones. 3.2. Administración de justicia. 3.2.1. Proceso penal. 3.2.2. Organización judicial. 3.3. Control político. 4. Políticas económicas. 5. Epílogo. 6. Bibliografía.

\section{Planteamiento}

En términos político-criminales, analizar el binomio derecho penal económicocorrupción pública supone afrontar una realidad de zonas superpuestas: la de los delitos de corrupción como modalidad específica de los delitos socioeconómicos.

Para acotar lo que, en la realidad criminológica española, debe entenderse por corrupción -y el procedimiento es, mutatis mutandis, válido en Derecho comparado-, la doctrina más aceptada toma como referencia inicial los "delitos contra la Administración Pública", del Código Penal español (CPE), Libro II, Título XIX, además de la corrupción en las relaciones económicas internacionales (art. 286 ter), que, aun situada entre los delitos socioeconómicos por la Ley Orgánica (LO) 1/2015, acoge conductas que afectan a funcionarios y, por ende, a la función pública.

Con este punto de partida normativo, sería recomendable introducir alguna corrección. Tal como hace el Consejo General del Poder Judicial (CGPJ) en su 
"Repositorio de procesos sobre corrupción"1, habría que excluir, de entre los delitos del Título XIX, el abandono de destino, las desobediencias y la denegación de auxilio, que no dan los perfiles criminológicos de la corrupción; e incluir la prevaricación en materia de ordenación del territorio, urbanismo y patrimonio histórico (arts. 320 y 322 CPE). También procede -en este caso, en contra de lo propuesto por el CGPJ- incluir la prevaricación en materia de medio ambiente (art. 329) y los cohechos protagonizados por particular, que no son sino la otra cara de la moneda de los cometidos por autoridad o funcionario público.

Situados en una panoplia normativa tan amplia, pretender encontrar los elementos comunes configuradores de una única categoría de corrupción pública -de la que la corrupción política sería una modalidad especial, solo diferenciada por elementos de matiz- puede ser garantía de simplificación, en detrimento del análisis científico, que exige profundizar en las diferencias y definir perfiles².

En efecto, en el estudio de la corrupción, los criterios dogmáticos y criminológicos invitan a separar los delitos sinalagmáticos, ligados a la idea de "pacto" entre partes ${ }^{3}$, de los que no lo son; los delitos de funcionarios, de los comunes, que puede cometer cualquiera; los delitos de resultado lesión, de los delitos de peligro; los delitos de enriquecimiento, objeto prioritario del Convenio penal sobre la corrupción ${ }^{4}$, de los que no lo producen, etc.

La presencia, evidente, de criterios diferenciales cuestiona el recurso a análisis homologadores y reduccionistas de la diversidad, que pueden conducir a una simplificación conceptual, contra la que previene De La Mata, cuando, a propósito del cohecho, critica manejar un concepto unitario de corrupción para aludir a conductas que, por afectar a bienes jurídicos distintos, solo pueden ser valoradas atendiendo, en cada caso, al comportamiento específico esperado del funcionario ${ }^{5}$.

La advertencia es más que razonable. Este trabajo, sin embargo, se sitúa en el plano político-criminal, que es el más indicado en el actual momento político-electoral

1 http://www.poderjudicial.es/cgpj/es/Temas/Transparencia/Repositorio-de-datos-sobre-procesospor-corrupcion/ . Consulta: 25.04.2019.

2 Gıııı, G.A., Cómo se investiga. Guía de investigación social para no especialistas, Avance, Barcelona, 1971, pp. 177-178.

3 Rotsch, T., “Corrupción y compliance", en Gómez Martín, V., Montiel, J.P., y Satzger, H. (eds.), Estrategias penales y procesales de lucha contra la corrupción, Marcial Pons, Barcelona, 2018, p. 234.

4 Convenio n 173 del Consejo de Europa, Estrasburgo, 27.01.1999. En https://www.boe.es/diario boe/txt.php?id=BOE-A-2010-12135 . Consulta: 25.04.2019.

5 De La Mata Barranco, N.J., La respuesta a la corrupción pública. Tratamiento penal de la conducta de los particulares que contribuyen a ella, Comares, Granada, 2004, p. 287. 
español. Y, en ese plano, interesan los delitos ya relacionados, que, aun siendo heterogéneos, integran como denominador común la noción etimológica de la corruptio, esto es, alteración por descomposición. 0, en lo normativo, alteración por desviación respecto a los "intereses generales... con sometimiento pleno a la ley y al Derecho", que es lo que impone el art. 103 de la Constitución Española (CE).

Si seguimos la terminología de chascarrillo popularizada por un ex-Director General de la Policía, pero multi-utilizada por la clase política española ${ }^{6}$ el funcionario se desvía de esos parámetros constitucionales tanto cuando "mete la mano" (en forma de malversación o cohecho), como cuando, simplemente, "mete la pata" (en forma de prevaricación).

En realidad, la agrupación de ambas morfologías delictivas bajo la etiqueta de "corrupción" no es nueva. De la primera de ellas -las decisiones ilícitas, con o sin estímulos pecuniarios- deja constancia don Quijote, cuando, al loar las capacidades de Sancho para asumir el gobierno de la ínsula Barataria, advierte: "Ya por muchas experiencias sabemos que no es menester ni mucha habilidad ni muchas letras para ser uno gobernador, pues hay por ahí ciento que apenas saber leer, y gobiernan como unos girifaltes"7. De la segunda, Sancho, cuando, en carta a su mujer Teresa Panza, programa y promete: "de aquí a pocos días me partiré al gobierno, adonde voy con grandísimo deseo de hacer dineros, porque me han dicho que todos los gobernadores nuevos van con este mismo deseo; ... así que, por una vía o por otra, tú has de ser rica"8.

\section{Corrupción pública y delincuencia socioeconómica}

En esta línea, y ya en nuestro siglo, el caso Odebrecht ha supuesto, en el universo político, jurídico y económico latinoamericano, un clamoroso ejemplo de corrupción transfronteriza ${ }^{9}$, en el que, como es obvio, se acumulan delitos de diferentes morfologías:

6 https://www.huffingtonpost.es/2014/12/03/cotino-meter-mano_n_6260002.html. Consulta: 25.04.2019.

7 De Cervantes Saavedra, M., El ingenioso hidalgo don Quijote de la Mancha, edición digital basada en la de Ediciones de La Lectura, Madrid, 1911-1913, Segunda parte, Capítulo XXXII. En http://www. cervantesvirtual.com/obra-visor/el-ingenioso-hidalgo-don-quijote-de-la-mancha-6/html/05f866994b53-4d9b-8ab8-b40ab63fb0b3 _ 16.html\#I_ 119 _. Consulta: 25.04.2019.

8 De Cervantes Saavedra, M., (2), El ingenioso hidalgo don Quijote de la Mancha, edición digital basada en la de Ediciones de La Lectura, Madrid, 1911-1913, Segunda parte, Capítulo XXXVI. En http://www. cervantesvirtual.com/obra-visor/el-ingenioso-hidalgo-don-quijote-de-la-mancha-6/html/05f866994b53-4d9b-8ab8-b40ab63fb0b3 _ 17.html\#I_ 125 _. Consulta: 25.04.2019.

9 Signor, R., Love, P. E. D., Valim, J. B.C., Raupp, A., y Olatunu, O., "It's Not Collusion Unless You Get Caught: The Case of 'Operation Car Wash' and Unearthing of a Cartel", en Journal of Antitrust Enforcement, Oxford, 2019. En https://www.academia.edu/38472281/lt_s_Not_Collusion_Unless_You_Get_Caught _ The _ Case _of _Operation_Car_Wash_and_Unearthing _ of _ a _ Cartel. Consulta: 25.04.2019. 
prevaricaciones sin aparente contenido económico, delitos contra la competencia, delitos de aprovechamiento -como blanqueo de activos o fraudes tributarios-, tráfico de influencias, etc. Pero todos ellos giran en la órbita en la que confluyen delitos de enriquecimiento de funcionarios públicos y de quienes no lo son. Surge en este punto una relación sinalagmática, en cuya virtud el comportamiento contra legem del funcionario beneficia al particular corruptor; y la dádiva de este beneficia al corrupto ${ }^{10}$.

Es aquí donde aparecen zonas secantes compartidas por la corrupción pública y la criminalidad económica.

En primer lugar, porque en el Estado desregulado de la globalización liberal, la intervención pública en la economía, que ha dejado de ser política económica para transformarse en funcional gobernanza, se externaliza y delega en corporaciones privadas. Y en lo que queda de Estado Social de Derecho, que no declina sus responsabilidades de dirección de los mercados, esta se materializa igualmente a través de entidades que actúan siguiendo las reglas del Derecho privado ${ }^{11}$ : por ejemplo, sociedades mercantiles públicas -del CPE, art. 31 quinquies-, que, sin perder su naturaleza mercantil, ejecutan políticas públicas o prestan servicios de interés económico general.

Así, en ambos modelos, la actividad política lícita de autoridades y funcionarios interactúa con la actividad económica de las sociedades mercantiles. Y la actividad ilícita de autoridades y funcionarios corruptos se entremezcla con delitos contra el orden socioeconómico protagonizados por el corruptor privado, ya persona física, ya persona jurídica.

Por otra parte, la corrupción, que descompone el funcionamiento de las administraciones públicas, genera también efectos negativos de contenido económico, como vaciamiento de las arcas públicas, distorsión del mercado, beneficios ingentes que requieren ser blanqueados, lesividad insoportable para bienes jurídicos colectivos, impulso pro-delictivo al funcionario probo, menos retribuido económicamente que sus colegas delincuentes, etc. En el otro lado, los agentes "corruptores", delincuentes ocupacionales, suelen servirse de estructuras organizadas de morfología empresarial, que pagan por la corrupción del funcionario un precio, tan alto como altas sean sus competencias, para obtener rendimientos no asequibles habitualmente a la delincuencia patrimonial y solo posibles en el entorno de las grandes obras y servicios públicos, 0 de las privatizaciones que garantizan una rentabilidad desmesurada. La contrapartida

10 Vergottinı, G., "Una road contro la corruzione", en Percorsi Constituzionali, CEDAM, Padova, 2012 (1/2). En http://magna-carta.it/content/road-map-contro-corruzione. Consulta: 25.04.2019.

11 Kuduch, H., "Corrupción y proceso penal”, en Gómez Martín, V., Montiel, J.P., y Satzger, H. (eds.), Estrategias penales y procesales de lucha contra la corrupción, Marcial Pons, Barcelona, 2018, p. 205. 
de los exorbitantes beneficios es el menoscabo de derechos e intereses de mayorías sociales, damnificadas por la asignación aberrante de los recursos públicos y por la supeditación de los "intereses generales" a los particulares"12.

Especialmente preocupante, para los adalides del mercado libre y de la consiguiente inhibición institucional en el juego económico, debería ser el mecanismo multiplicador de delincuencia activado por la corrupción: el soborno corporativo es, en la línea que subyace a la Foreing Corrupt Practices Act, esencialmente destructivo para la libre competencia ${ }^{13}$, y consolida marcos económicos en los que el empresario que no corrompe no puede competir. Ha de abandonar el campo de batalla en manos del competidor desleal, que dedica sus recursos no al desarrollo de tecnologías innovadoras, a modos de producción sostenible 0 a favorecer las condiciones necesarias para un trabajo decente, sino a sobornar. Los fondos públicos, a su vez, sufragan, con injustificables sobreprecios, proyectos inidóneos y terminan imponiéndose las opciones menos eficientes. No puede, pues, sorprender el dato, avalado por múltiples investigaciones, de que máxima corrupción institucional coincide con máxima pobreza social, mientras que las condiciones de vida más aceptables se dan en los países que registran menores índices de degradación en sus administraciones públicas ${ }^{14}$.

Así, la corrupción pública se integra en los esquemas de la criminalidad económica. Y así las afronta, en España, la Fiscalía Especial contra la Corrupción y la Criminalidad Organizada, para la que la corrupción se ha privatizado en la medida en que aparece vinculada a delitos -como blanqueo de capitales, fraudes tributarios, delitos urbanísticos o contra el mercado y los consumidores- propios de la criminalidad económica organizada, cuyos modos de actuación, sobre todo en lo atinente a la rentabilización de beneficios, copian también los corruptos ${ }^{15}$. Y Transparencia Internacional, en su

12 LaBoRDE, D. M., "Interfaz entre corrupción pública transnacional y derechos humanos. Respuesta penal integrada", en Ramírez Barbosa, P.A., (dir.), Desafíos del Derecho Penal en la sociedad del siglo XXI. Libro Homenaje a Ignacio Berdugo Gómez de la Torre, Temis, Bogotá, 2018, pp. 217-221.

13 Ramírez Barbosa, P.A., "La Ley contra las prácticas corruptas en el extranjero. La FCPA de Estados Unidos: "Compliance", extraterritorialidad y responsabilidad de la persona jurídica. Reflexiones acerca del caso Odebrecht", en Ramírez Barbosa, P.A., (dir.), Desafíos del Derecho Penal en la sociedad del siglo XXI. Libro Homenaje a Ignacio Berdugo Gómez de la Torre, Temis, Bogotá, 2018, p. 5.

14 Pérez Cepeda, A.I., y Benito Sánchez, D., "La política criminal internacional contra la corrupción", en Berdugo Gómez de la Torre, I., y Liberatore Bechara, A.E., (coord.), Estudios sobre la corrupción. Una reflexión hispano-brasileña, Centro de Estudios Brasileños-Universidad de Salamanca, Salamanca, 2013, pp. 19-20.

15 Fiscalía General del Estado, Memoria 2018, pp. 478-479. En https://www.fiscal.es/fiscal/ PA_WebApp_SGNTJ_NFIS/descarga/memoria2018_fiscalia _ anticorrupcion. pdf?idFile=b694282b-c7f6-4af4-8116-f5a437beaa5b. Consulta: 25.04.2019. 
estrategia anticorrupción, propone unos "Principios de transparencia y prevención para las empresas", que van dirigidos tanto a potenciar la competencia leal como a reducir la incidencia de los intereses privados en la corrupción pública ${ }^{16}$.

Son solo dos pronunciamientos institucionales que marcan líneas determinantes en el diseño de las estrategias político-criminales anticorrupción.

\section{Apuntes político-criminales}

Estas estrategias han de cuestionarse inicialmente su propia legitimidad; lo que equivale a preguntarse sobre la necesidad -el principio de intervención mínima no se conforma con la legitimación por la conveniencia- y las formas -el si y el como- de la reacción penal frente a las conductas de corrupción, lo que en el plano político da lugar al debate sobre los riesgos de judicialización de la gestión pública.

Judicialización de la política es, desde que en el año 2000 Stone-Sweet publicara su influyente monografía Governing with Judges: Constitutional Politics in Europe, tanto como influencia de las cortes constitucionales en las demás instancias -parlamentarias, judiciales y ejecutivas- del Estado-, influencia abocada a transformar las controversias políticas en cuestiones jurídicas ${ }^{17}$. En el contexto específico del debate sobre las opciones político-criminales a implementar frente a la corrupción, se entiende por judicialización el disfuncional exceso intervencionista de la justicia penal, que interfiere la actividad de las administraciones públicas, con el inevitable efecto, denunciado por Capella, de que los conflictos entre los agentes especializados en la intermediación política quedan sometidos a la decisión judicial, lo que "arruina inevitablemente la neutralidad institucional de los jueces, cuyas decisiones pasan a ser bazas favorables o contrarias en la disputa política, e inevitablemente han de ser contrapesadas con otras bazas"18.

Resulta correcta esta llamada al alejamiento de los jueces de la "disputa política". Pero "disputa política" y delincuencia se mueven en planos cualitativamente distintos. Y, si es cierto que resulta procedente que la Justicia se mantenga alejada de los excesos en el juego político, no lo es menos que, frente a los delitos de corrupción, no parece procedente un adelgazamiento de la respuesta penal, tal como el registrado en Italia,

16 http://transparencia.org.es/principios-de-transparencia-para-empresas/ . Consulta: 25.04.2019.

17 Ferejohn, J., "Judicializing Politics, Politicizing Law", en Law and Contemporary Problems, 2002 (65), Durham, p. 42. En http://scholarship.law.duke.edu/lcp/vol65/iss3/3 . Consulta: 25.04.2019.

18 Capella, J-R., "Contra la judicialización de la política", en Mientras tanto.e, 2006 (42), Barcelona. En http://www.mientrastanto.org/boletin-42/notas/contra-la-judicializacion-de-la-politica. Consulta: 25.04.2019. 
a comienzos del siglo, con resultados poco halagüeños ${ }^{19}$. El dontancredismo penal, en esta materia, deviene complicidad.

La respuesta político-criminal, para ser, además de legítima, eficaz, debe integrarse en estrategias políticas más amplias ${ }^{20}$. En concreto, dado que la corrupción se nutre de sinergias y dependencias recíprocas entre el sujeto generador de decisiones políticas y el particular interesado en lucrarse de ellas, la lucha anticorrupción ha de incorporar: a) estrategias político-criminales y organizacionales dirigidas a blindar la independencia y lealtad institucional de los servidores públicos; y b) estrategias que incidan en las estructuras económicas, yugulando ab origine los factores de interferencia ilícita en el trabajo de las administraciones ${ }^{21}$.

\subsection{Derecho penal sustantivo}

Las figuras más tradicionales de corrupción (cohecho, tráfico de influencias, prevaricación, malversación, negociaciones prohibidas a los funcionarios, etc.) gozan de acogida tradicionalmente profusa en el Derecho penal comparado ${ }^{22}$. Se trata de delitos construidos en torno a la figura de la autoridad o funcionario que, en el ejercicio de su cargo, actúa favoreciendo intereses privados, propios y/o ajenos, en detrimento de los públicos, cuya tutela y promoción tiene asignadas ${ }^{23}$.

La mera criminalización de una conducta no comporta, sin embargo, su erradicación. De hecho, es frecuente -y razonada- la acusación al Derecho penal sustantivo de ser escasamente eficaz en la materia. Lo que, como también es frecuente, ha empujado al legislador a afrontar estos delitos recurriendo al procedimiento, tan manido como

19 Viganò, F., "I delitti di corruzione nell'ordinamento italiano: qualche considerazione sulle reforme già fatte, e su quel che resta da fare", en Puente Aba, L.M., (edit.), Economía y Derecho Penal en Europa: una comparación entre las experiencias italiana y española. Actas del Congreso hispano-italiano de Derecho Penal Económico", Universidade da Coruña, A Coruña, 2015, p. 93.

20 De La Cuesta Arzamend, J. L., "La corruption: réponses internationales et européennes à un phénomène nécessitant une politique criminelle intégrale", en Céré, J.P. y Japiassú, C. E., (dir.), Corruption et Droit penal, L.'Harmattan. Paris, 2019, p. 160.

21 Terradillos Basoco, J.M., "Corrupción, globalización y Derecho Penal Económico”, en Demetrio Crespo, E., y González Cuellar Serrano, N. (dir.), Halcones y palomas. Corrupción y delincuencia económica, Castillo de Luna. Ediciones Jurídicas, Madrid, 2015, p. 25.

22 Reátegu Sánchez, J., "Los delitos de corrupción de funcionario y criminalidad organizada", en Revista de Derecho Penal. Delitos contra la Administración Pública-II, Rubinzal-Culzoni, Buenos Aires, 2004, p. 317.

23 Acale Sánchez, M., “Delitos contra la Administración Pública (II)”, en Terradillos Basoco, J.M. (coord.), Lecciones de Derecho Penal. Parte Especial, tomo IV, Editorial Jurídica Continental, San José (Costa Rica), 2016, p. 247. 
constatadamente inane, de ampliar el ámbito de conductas punibles o de intensificar la contundencia de las penas ${ }^{24}$. Se trata de opciones que, históricamente, han servido, en clamorosa "huida al Derecho penal", para que los poderes públicos redujeran sus compromisos político-criminales a reformas de la ley penal-siempre fáciles 0 , incluso, electoralmente rentables-, en clave punitivista, olvidando otros mecanismos jurídicos de prevención que, aunque más complejos y costosos, resultan más eficaces ${ }^{25}$.

Parecen más convincentes las estrategias legiferantes dirigidas a sustituir el primitivo arsenal normativo por otro más sofisticado, adecuado a las necesidades del siglo XX|26, sustentado en dos criterios-guía: a) tutela de la Administración no como aparato jerarquizado, sino como servicio público a los derechos constitucionales de los ciudadanos, y b) responsabilidad penal específica del servidor público, considerando tal a todo sujeto que, más allá de las actuales definiciones legales -artículos 24 y 427 del $C P$, en el caso españo| ${ }^{27}{ }_{-}$, cuente con capacidad jurídica para tomar decisiones que repercutan materialmente en los intereses confiados a la Administración.

\subsubsection{Delitos}

El paso siguiente, examen crítico de los diferentes delitos de corrupción, no puede abordarse aquí en detalle. Nos detendremos en solo dos ejemplos significativos.

El primero, el enriquecimiento ilícito, delito ausente -si no es por la vía indirecta del comiso- en el CPE, que goza de amplia acogida en los ordenamientos latinoamericanos (CP de la Nación Argentina, art. 268 (2); CP Federal de los Estados Unidos Mexicanos, art. 224; Venezuela, Ley Contra la Corrupción, artículos 43 y 73; CP Colombiano, art. 412, etc.). En Europa, Francia, en el art. 321-6 CP, castiga un delito de no justificación del tren de vida o del origen de los bienes, aunque exige la constancia de relaciones habituales con una 0 varias personas que se dediquen a la comisión de crímenes 0 de delitos castigados con pena de, al menos, cinco años de prisión.

En la medida en que, en la generalidad de casos, se castiga no el enriquecimiento sino la ausencia de justificación del patrimonio acumulado, con la consiguiente e

24 Berdugo Gómez De La Torre, I., “Corrupción y Derecho penal, Condicionantes internacionales y reformas del Código Penal", en Demetrio Crespo, E., y González-Cuéllar Serrano, N. (dir.), Halcones y palomas: corrupción y delincuencia económica, Castillo de Luna. Ediciones Jurídicas, Madrid, 2015, p. 66.

25 Jiménez Villarejo, C., "Contra la corrupción: más trasparencia, más prevención", en Revista de la Facultad de Derecho de la Universidad de Granada, 2006 (9), p. 535.

26 MeINI, I., Delitos contra la Administración Pública, USAID, Ciudad de Guatemala, 2008, p. 5.

27 Acale Sánchez, M., “Delitos contra la Administración Pública (II)”, cit., p. 254. 
inevitable inversión de la carga de la prueba ${ }^{28}$, el debate sobre su constitucionalidad sigue abierto, aunque la doctrina mayoritaria se inclina por negarla, porque contraría garantías procesales elementales del imputado ${ }^{29}$, que sigue siendo titular del derecho constitucional a la presunción de inocencia, con todos sus corolarios, aunque haya asumido voluntariamente el desempeño de funciones públicas ${ }^{30}$.

Sí cuenta el ordenamiento español con la criminalización expresa de los fraudes y exacciones ilegales, pero en términos que aconsejan su revisión.

El art. 438 CPE castiga, en efecto, al funcionario que, con abuso de su cargo, cometiere la defraudación de prestaciones de la Seguridad Social descrita en el art. 307 ter. La pena es la de este precepto (prisión de seis meses a tres años en el tipo básico), en su mitad superior (de un año y nueve meses a tres años), "pudiéndose llegar hasta la pena superior en grado". Pero si el fraude a la Seguridad Social revistiere la forma agravada, por ejemplo, por exceder de cincuenta mil euros, la pena de prisión sería de dos a seis años, y la pena superior, correspondiente a la autoridad o funcionario del art. 438, tendría una duración de seis a nueve años.

Si se analiza el tipo de referencia, el del art. 307 ter, se advierte que el funcionario castigado por el art. 438 es el que facilita el disfrute fraudulento de prestaciones indebidas a un trabajador. Sin embargo, si el mismo funcionario presta idéntica colaboración al empresario que, por impago o percepción indebida de cuotas, defrauda la misma cuantía, sería castigado, como cooperador necesario del art. 307, con prisión de uno a cinco años; 0 de seis meses a un año si los jueces le rebajan la pena, como cooperador extraneus, en los términos del art. 65.3. Siempre muy por debajo de los nueve años de prisión que le corresponderían si hubiere ayudado al trabajador. Así, la discriminación punitiva que imponen, en los delitos contra la seguridad social, los artículos 307 y 307 ter en razón de la condición personal del defraudador -empresario en un caso, trabajador en el otro ${ }^{31}$-, se extiende y potencia en el art. 438 cuando intervienen en el fraude funcionarios públicos.

28 Gimeno Beviè, J., "Algunos problemas procesales en la recuperación de activos"; en Nieto Martín, A., y Maroto Calatayud, M., (dir.), Public Compliance. Prevención de la corrupción en administraciones públicas y partidos políticos, Universidad de Castilla-La Mancha, Cuenca, 2014, p. 285.

29 Medina Salas, M.A., "Consideraciones sobre la inconstitucionalidad del delito de enriquecimiento ilícito", en Capítulo Criminológico, Maracaibo, 2009 (37-1), p. 151.

30 Sandhagen, A., "La inversión de la carga de la prueba. A propósito del delito de enriquecimiento ilícito de funcionario público y la aplicación de la teoría de las cargas dinámicas de la prueba", en Revista de Derecho Penal, 08.04.2017, Buenos Aires, p. 19. En http://www.pensamientopenal.com. ar/doctrina/47526-inversion-carga-prueba-proposito-del-delito-enriquecimiento-ilicito-funcionario . Consulta: 25.04.2019.

31 Terradillos Basoco, J.M., y Boza Martínez, D., El Derecho penal aplicable a las relaciones laborales. Lecciones., Bomarzo, Albacete, 2017, p. 171. 


\subsubsection{Sanciones}

Tal como es regla en materia de delincuencia económica, es aconsejable mantener frente a corruptos y corruptores la amenaza de penas privativas de libertad ${ }^{32}$, que, en su configuración legal, sean susceptibles de cumplimiento efectivo. No es necesario que se ejecuten siempre intramuros, pero sí que exista una posibilidad creíble de que la individualización judicial así lo decida, lo que resultará relevante para el delincuente de cálculo.

La conminación de penas meramente pecuniarias o limitativas de derechos distintos a la libertad ambulatoria tiene eficacia preventiva limitada. Aquellas son fácilmente eludibles o compensables33; estas, no intimidan. De ahí que seguir la línea punitiva del CPE -bien distinta a la de los artículos 413 y siguientes del CP Colombiano- de reservar para los delitos de corrupción sin enriquecimiento -señaladamente, prevaricaciónpenas de inhabilitación especial, renunciando a la prisión, sea tanto como renunciar anticipadamente a cualquier efecto preventivo general, puesto que la amenaza penal queda reducida a nada cuando se limita a privar de cargos públicos a funcionarios corruptos, políticamente estigmatizados, que, de hecho, ya no podrán acceder a ellos, al menos mientras [creamos que] las decisiones populares a la hora de elegir a sus autoridades políticas respondan a criterios de racionalidad ${ }^{34}$. También se renuncia a la prevención especial: las penas de inhabilitación, con efectos solo en el ámbito público (CPE, art. 42), no evitan la recolocación del condenado en circuitos de actividad con trascendencia pública, tal como prueba el omnipresente mecanismo de las "puertas giratorias", en cuya virtud el inhabilitado para un puesto en la Administración accede a otro distinto, pero igualmente público ${ }^{35}, 0$ asume funciones en la empresa privada que le mantienen en estrecho contacto con los ámbitos en los que había delinquido.

32 Jareño Leal, A., "La corrupción en la contratación pública", en Pasajes. Revista de pensamiento contemporáneo, 2013 (42), p. 18. En http://roderic.uv.es/bitstream/handle/10550/45549/14-21. pdf? sequence $=1$ cisAllowed $=y$. Consulta: 25.04.2019.

33 Terradillos Basoco, J.M., "Penas privativas de otros derechos. Penas accesorias. Pena de multa", en Berdugo Gómez de la Torre et alii, Curso de Derecho Penal. Parte General, $3^{\text {a }}$ ed., Experiencia, Barcelona, 2016, p. 492.

34 Castro Cuenca, C. G., "Derecho penal y lucha contra la corrupción en el siglo XXI", en Ramírez Barbosa, P.A., (dir.), Desafíos del Derecho Penal en la sociedad del siglo XXI. Libro Homenaje a Ignacio Berdugo Gómez de la Torre, Temis, Bogotá, 2018, p. 280.

35 Si no lo evita una correcta interpretación teleológico-funcional de los preceptos inhabilitadores, como la realizada en la Sentencia del Tribunal Supremo español, Sala de lo Contencioso-Administrativo, sección 4a núm.438/2019, de 01.04.2019, Fundamento de Derecho Décimo. 
El aconsejable recurso a la pena privativa de libertad no es incompatible con las penas de inhabilitación y de privación del derecho de sufragio pasivo del funcionario corrupto -tal como recomienda Transparencia Internacional ${ }^{36}$-, siempre que sean de larga duración, porque es necesario apartarlo efectivamente del entorno que favoreció la comisión del delito ${ }^{37}$.

En el caso del particular corruptor, también puede resultar idóneo añadir a la pena carcelaria las inhabilitaciones especiales. Por consideraciones profilácticas elementales, debe ser separado del ejercicio de la actividad económica que hizo posible su contacto contaminante con la Administración Pública. Y para reforzar los resultados preventivos esperados, la inhabilitación debe ir acompañada de otras penas privativas de derechos, como prohibición de contratar con el sector público, prohibición de recibir subvenciones 0 ayudas públicas, beneficios 0 incentivos fiscales 0 del sistema de previsión social, 0 prohibición de intervenir en transacciones comerciales de trascendencia pública. EI CPE cuenta con estas penas, pero no las prevé, y quizá fuera conveniente hacerlo, para los funcionarios condenados por delitos de cohecho o de tráfico de influencias.

Las penas pecuniarias, que muestran al eventual delincuente la labilidad no solo de los beneficios económicos del delito sino también de su propia riqueza previa, deben resultar suficientemente inhibidoras, lo que requiere que sean proporcionales al beneficio objetivamente perseguido en la operación delictiva ${ }^{38}$. Sería, en efecto, poco útil adecuar la cuantía de la multa proporcional al caudal económico del culpable, en un ámbito en el que tan frecuente es la intervención de insolventes "hombres de paja" y tan asequible la ocultación de los frutos del delito. Y tampoco resultaría útil -en clave preventiva- que la multa se fijara por referencia al beneficio obtenido, que puede resultar muy inferior al calculado, siendo así que la eventual cuantía de este es el dato que se integra en el proceso de toma de decisiones por parte del delincuente.

La advertencia de que la multa ha de ser, por su cuantía, seriamente intimidante es tanto más oportuna en el caso de la condena a personas jurídicas, cuyo volumen de facturación alcanza cifras tan elevadas que a su lado palidecen las multas por cuotas legalmente previstas ${ }^{39}$.

36 http://webantigua.transparencia.org.es/partidos_ politicos/nota_ti_contra _ corrupcion.pdf. Consulta: 25.04.2019.

37 VergottinI, G., "Una road contro la corruzione", cit.

38 Terradillos Basoco, J.M., "Mercado y Administración pública (Criminalidad económica y corrupción política", en Medina Cuenca, A., (coord.), El Derecho penal en tiempos de cambios. Libro Homenaje al profesor Luis Fernando Niño, Unijuris, La Habana, 2016, pp. 155-156.

39 Neira Pena, A. M., "Colaboración público-privada como estrategia para combatir la corrupción: el sistema de responsabilidad penal de las personas jurídicas y los programas de prevención delictiva", 
Los indultos constituyen una vía hacia la impunidad. Originariamente vinculados, en su legitimación, a consideraciones de oportunidad, corren el riesgo de deslizamiento hacia la arbitrariedad, cuando su concesión resulta sensible a la presión de quienes ejercen el poder político 0 económico ${ }^{40}$. Quizá por ello, los condenados por corrupción han estado históricamente sobrerrepresentados en la obtención de indultos ${ }^{41}$. Se impone, pues, reducir drásticamente su número y racionalizar su concesión.

En esta línea, y como respuesta al clamor popular que reivindicaba un replanteamiento global de la institución del indulto y su supresión en materia de corrupción, en España la L0 1/2015 modificó la Ley de Reglas para el ejercicio de la Gracia de indulto, de 18 de junio de 1870 (!), estableciendo la obligación del Gobierno de remitir semestralmente al Congreso de los Diputados un informe sobre concesión y denegación de indultos. La respuesta, con toda evidencia, no afronta el problema en toda su complejidad, aunque la reducción de la cifra de indultos ha sido, más por la presión popular que por la idoneidad de la reforma legal, llamativa: 520 en 2006; 521 en 2007; 501 en 2012, 26 en 2017, 17 en $2018^{42}$.

Otro problema al que no se ha dado respuesta jurídico-penal eficaz es el de la irrecuperabilidad de los fondos delictivamente sustraídos al control público, esos fondos que "nunca nadie en la historia de América Latina ha sido obligado a devolver"43. Las responsabilidades civiles son, en efecto, objeto de más que frecuente elusión, lo que, en delitos de enriquecimiento, supone tanto como despreciar los derechos de los damnificados (en el caso de la corrupción política, los derechos de todos) y renunciar a los efectos preventivos derivados de la advertencia seria, dirigida al eventual delincuente, de que la rentabilidad económica del delito es sumamente lábil.

La actual regulación del decomiso en el CPE tiene origen europeo, concretamente en la Decisión Marco 2005/212/jai del Consejo de la Unión Europea (UE) y en la Directiva 2014/42/DUE, relativas al decomiso de los productos, instrumentos y bienes relacionados con el delito, a fin de que los Estados adapten sus legislaciones penales a un modelo de comiso similar en el espacio europeo.

en Puente Aba, L.M., (dir.), La proyección de la corrupción en el ámbito penal: análisis de una realidad transversal, Comares, Granada, 2017, p. 121.

40 Grupo De Estudios De Política Criminal, Una alternativa a algunas previsiones penales utilitarias. Indulto, prescripción, dilaciones indebidas y conformidad procesal, Tirant lo Blanch, Valencia, 2014. En http://www.gepc.es/web/sites/default/files/ficheros/libro15 _ 0.pdf. Consulta: 25.04.2019.

41 Álvarez García, F.J., "Las prioridades de la justicia criminal”, en Álvarez García, F.J. (dir.), Estudio crítico sobre el Anteproyecto de Reforma Penal de 2012, Tirant lo Blanch, Valencia, 2013, p.45.

42 https://www.eldiario.es/politica/Indultos_ _ _ 856014656.html. Consulta: 25.04.2019.

43 Galeano, E., Patas arriba. La escuela del mundo al revés, $1^{\text {a }}$ edic., Catálogos, Buenos Aires, 2006, p. 88. 
24 Apuntes político-criminales en torno a la corrupción pública como delincuencia socioeconómica organizada.

El caso español - Juan M. Terradillos Basoco

Así, hoy cuenta el CPE con cinco tipos de decomiso: directo u ordinario (art. 127), de valor equivalente (arts. 127.3, 127 bis 3, 127 quater y 127 septies), ampliado y/o por actividad delictiva previa continuada (art. 127 bis y 127 quinquies y sexies), decomiso sin sentencia (art. 127 ter), y decomiso de bienes de terceros (art. 127 quater) $)^{44}$.

Sobre la naturaleza del decomiso, de necesaria conceptualización para determinar coherentemente sus líneas rojas, el legislador español, en la Exposición de Motivos de la L0 1/2015, acepta las tesis del Tribunal Constitucional (TC) alemán, que niegan al decomiso -que allí alcanza solo a las ventajas patrimoniales obtenidas por el delito- la naturaleza de pena 0 de sanción asimilada, y que consideran pena accesoria a la confiscación de los productos e instrumentos del delito. Pero en Derecho español, al igual que en otros muchos ordenamientos latinoamericanos, el decomiso comprende no solo las ganancias del delito, sino también sus efectos e instrumentos, lo que obliga a entender que, al menos en algunas de sus modalidades, tiene naturaleza penal. A partir de esa conclusión, surgen serias dudas sobre la constitucionalidad del decomiso ampliado de los artículos 127 bis quinquies y sexies del CPE; también del acordado aun sin sentencia condenatoria, del art. 127 ter, y del que recae sobre bienes transferidos a terceros, a los que según el artículo 127 quáter, se les pueden requisar esos efectos e instrumentos, aunque no conocieran su procedencia ilegal, o una cantidad equivalente si ya no los tuvieren en su poder ${ }^{45}$.

En favor de la constitucionalidad de las modalidades de decomiso ampliado, se argumenta, con palabras del Tribunal Europeo de Derechos Humanos, (Decisión 696/2005, Dassa Foundation vs Liechtenstein), que este no es una consecuencia sancionadora derivada del delito, sino "un mecanismo jurídico de recuperación frente a enriquecimientos ilícitos o injustos", de naturaleza más civil que penal. A partir de ahí, se infiere que, si el decomiso no es pena ni medida de seguridad ni (a pesar de que así lo denomina el CPE) consecuencia accesoria, se puede relativizar el rigor probatorio respecto a sus presupuestos fácticos: es necesaria su constatación, pero no en los términos exigidos para calificar los hechos delictivos como "probados", siendo suficiente "su precalificación delictiva o estimación previa indiciaria, por la autoridad judicial competente. Es necesaria su acreditación, pero sólo con base indiciaria"46.

44 Dolz LAGo, M. J., "Los decomisos: aproximación a sus aspectos sustantivos y procesales tras las reformas del 2015 (1)", en La Ley Penal, Madrid, 2017 (124), p. 3.

45 Rolg Torres, M., "El comiso como estrategia frente a la corrupción en Alemania: interpretación jurisprudencial", en Estudios Penales y Criminológicos, Santiago de Compostela, 2018 (XXXVIII extr.), pp. 599-600. En http://www.usc.es/revistas/index.php/epc/article/view/4473 . Consulta: 25.04.2019.

46 Dolz LAGo, M. J., "Los decomisos: aproximación a sus aspectos sustantivos y procesales tras las reformas del 2015 (1)", cit., pp. 4-5. 
En contra, y más razonablemente, se ha argumentado que todas las formas de ampliación del decomiso prescinden de los principios de culpabilidad y de peligrosidad, liberan de la carga de la prueba sobre el delito previo a las partes acusadoras, olvidando que el decomiso es, en el CPE (art. 127), una consecuencia accesoria a las penas, y facultan la averiguación inquisitorial del patrimonio de quien es solo sospechoso de delito y de todos los que tienen o tuvieron relación con él. Todo ello resulta "complejo procesalmente y cuestionable penalmente" porque responde al propósito de ahorrar el esfuerzo probatorio requerido por toda condena penal ${ }^{47}$.

A pesar de la amplitud de supuestos, evanescencia de límites, flexibilidad de definiciones y frecuente admisión de presunciones, las continuadas reformas legales que en España han afectado al decomiso (la última, por L0 1/2019, que, una vez más, amplía los ámbitos de intervención penal), no han logrado -al igual que ocurre en Derecho comparado ${ }^{48}$ resultados espectaculares en la recuperación de activos, y los que se han producido han de apuntarse, más que a una legalidad difícilmente conciliable con los principios generales del sistema penal, a la actuación de los medios técnicos puestos en marcha, especialmente a la Oficina de Recuperación y Gestión de Activos.

\subsection{Administración de justicia}

\subsubsection{Proceso penal}

La corrupción pública no es una novedad en el panorama político español, pero presenta hoy modalidades que ni remotamente pudieron estar entre los objetivos a los que apuntó el legislador de fines del XIX.

Es cierto que el Derecho penal sustantivo se ha ido reformando, no siempre felizmente, con pretensiones de aggiornamento y adaptación a una realidad criminológica cambiante; pero los instrumentos procesales no han seguido ese proceso. La Ley de Enjuiciamiento Criminal (LECrim), nacida en 1882, ha sido víctima de continuas labores de parcheado -la última, por Ley 41/2015- que han desordenado, aún más, su vetusta sistemática ${ }^{49}$, pero no han sido capaces de implementar un engranaje procesal apto para afrontar con agilidad y eficacia las modernas formas de delincuencia.

47 De La Mata Barranco, N. J., “El decomiso ide los bienes del delito?", en Almacén de Derecho, 18.11.2016. En https://almacendederecho.org/decomiso-los-bienes-del-delito/. Consulta: 25.04.2019.

48 Moneyval, Horizontal Review of Moneyval's Third Round of Mutual Evaluation Reports. Committee of Experts on the Evaluation of Anti-Money Laundering Measures and the Financing of Terrorism, Consejo de Europa, Strasbourg, 2010, p. 96. En https://rm.coe.int/horizontal-review-of-moneyval-s-thirdround-of-mutual-evaluation-repor/168071511d . Consulta: 25.04.2019.

49 Roma Valdés, A., "La persecución de los delitos de corrupción. Las dificultades de la cooperación internacional en los paraísos fiscales", en Puente Aba, L.M., (dir.), La proyección de la corrupción en el ámbito penal: análisis de una realidad transversal, Comares, Granada, 2017, p. 47. 
La incidencia sobre el proceso penal de poderosos factores -vinculados incluso a la tipificación legal50 - que obstaculizan materialmente la investigación y la independencia judicial, es relevante: en el ámbito público, el poder de los inculpados para maximizar la rentabilidad económica y garantizar la impunidad, y, en el lado privado, la implicación de complejas estructuras empresariales, frecuentemente transnacionales, refuerzan las posibilidades de evitar la sentencia condenatoria, y, si es que llega a pronunciarse, de eludir la ejecución de la pena carcelaria o pecuniaria o de burlar el decomiso de los bienes, lo que reduce a humo de pajas la pretendida capacidad desincentivadora de la norma penal.

En esas condiciones, la estadística penitenciaria española no sugiere una aplicación de la ley penal proporcionada a la valoración social de la extensión e intensidad de la corrupción. A 1.01.2019, cumplían condena por delitos de corrupción en las prisiones dependientes de la Administración General del Estado 94 internos, de ellos 84 penados. En Cataluña el número total era de 23, de ellos, 17 penados. La distribución por delitos, en las prisiones del Estado, era la siguiente: prevaricación 0; prevaricación de funcionario, 3; ordenación del territorio, 7; urbanismo, 3; malversación, 47; cohecho, $20^{51}$.

Para que la conminación penal no quede en agua de borrajas, el proceso ha de garantizar la investigación exhaustiva de los hechos; obstaculizada, sin embargo, por la Ley 41/2015, de 5 de octubre, de modificación de la LECrim para la agilización de la justicia penal y el fortalecimiento de las garantías procesales, que limitó la duración de la instrucción penal a seis meses -0, a instancias del ministerio fiscal, a dieciocho, prorrogables, si los asuntos resultaren complejos (LECrim, art. 324)-, con el riesgo de que la celeridad impuesta actúe como una no deseada "ley de punto final" y provoque, como efectos colaterales, el cierre apresurado de expedientes inconclusos ${ }^{52}$. Promesas electorales de reforma de la LECrim en este punto aún no han sido llevadas a la práctica.

A su vez, la proliferación de aforamientos (más de dieciocho mil; 0 doscientos cincuenta mil, si se incluye el de los miembros de las fuerzas y cuerpos de seguridad) constituye un elemento perturbador en el enjuiciamiento de la corrupción. Su desaparición está presente en propuestas electorales de los últimos años, pero solo ha comenzado a

50 Rodríguez Moro, L., "Análisis normativo y jurisprudencial de los delitos de tráfico de influencias de los arts. 428 y 429 del Código Penal. Especial referencia a la dificultad de prueba", en Puente Aba, L. M., (dir.), Corrupción y fraudes a consumidores: perspectivas y casos actuales, (Comares, Granada 2016, pp. 189-190.

51 http://www.poderjudicial.es/cgpj/es/Temas/Transparencia/Repositorio-de-datos-sobre-procesospor-corrupcion . Consulta: 25.04.2019.

52 http://politica.elpais.com/politica/2015/10/15/actualidad/1444895824_ 705434.html. Consulta: 25.04.2019. 
cristalizar en Andalucía, en cuyo parlamento autonómico se ha presentado, el 10.03.2019, una proposición de ley para suprimir los aforamientos de la clase política.

Por su parte, unos plazos de prescripción excesivamente cortos -que recompensan la artificiosa e interesada prolongación de trámites ${ }^{53}$ - pueden, también, enervar la eficacia de los procesos, garantizando la impunidad ${ }^{54}$. En un sector de la criminalidad caracterizado por la opacidad y en el que se acumulan las dificultades objetivas -y, entre ellas, el poder de que gozan los acusados- de investigación y persecución, siempre debe estar en el horizonte legislativo la adecuación de los plazos de prescripción, ajustándolos, entre otros criterios, a la probable dificultad de los delitos a examen ${ }^{55}$.

\subsubsection{Organización judicial}

La independencia de jueces y fiscales, que se enfrentan a sujetos detentadores de amplios poderes, cuya influencia perniciosa resulta difícilmente superable a los propios funcionarios de la Administración de justicia, es condición sine qua non del éxito de las estrategias anticorrupción.

Aunque jueces y magistrados pueden acudir al CGPJ y al Ministerio Fiscal cuando se consideren "inquietados o perturbados en su independencia" (Ley Orgánica del Poder Judicial, art. 14), la Red Europea de Consejos de Justicia, en sus informes de 2014 y 2015, refleja datos preocupantes: un $25 \%$ de jueces españoles afirman que algunos asuntos son asignados, al margen de las reglas de reparto, con el fin de influir en el resultado; el $75 \%$ creen positivamente que algunos jueces han sido nombrados por razones ajenas a su capacidad y experiencia; $85 \%$ afirma que la promoción profesional responde a criterios espurios; solo el 38\% mantienen que su independencia ha sido respetada por el Gobierno, y solo el 50\%, que ha sido respetada por el propio CGPJ; finalmente, el $50 \%$ cree que la limitación de recursos recorta su independencia ${ }^{56}$. Son datos que no puede dejar de lado la política criminal anticorrupción.

53 Rebollo Vargas, R., y Casas Hervilla, J., "Reflexiones, problemas y propuestas para la investigación de la delincuencia económica", en Revista General de Derecho Penal, Madrid, 2013 (19), p. 4.

54 Montiel, J.P., "Sobre la inoponibilidad de la prescripción y de la cosa juzgada en casos de corrupción (pública)", en Gómez Martín, V., Montiel, J.P., y Satzger, H. (eds.), Estrategias penales y procesales de lucha contra la corrupción, Marcial Pons, Barcelona, 2018, p. 194.

55 Grupo de Estudios de Política Criminal, Una alternativa a algunas previsiones penales utilitarias. Indulto, prescripción, dilaciones indebidas y conformidad procesal, cit., p. 13.

56 http://www.poderjudicial.es/cgpj/fr/Themes/Relations-internationales/Relations-internationalesinstitutionnelles/Europe/Reseau-europeen-des-conseils-de-la-justice/Rapports-RECJ/Resumen-delos-informes-2014-2015-de-la-Red-Europea-de-Consejos-de-Justicia--1--Independencia-y-rendicionde-cuentas-del-Poder-Judicial-y-de-la-Fiscalia--2--Estandares-judiciales-minimos-V--procedimientosdisciplinarios-y-responsabilidad-de-los-jueces---Espanol---Ingles-. Consulta: 25.04.2019. 
También es importante la independencia de la Fiscalía respecto al poder ejecutivo ${ }^{57}$ y su coherente vinculación exclusiva al principio de legalidad. Y no solo la independencia de la cúspide ${ }^{58}$; también la de los acusadores públicos subordinados frente a la eventual presión procedente de instancias externas o de la propia jerarquía fisca ${ }^{59}$. Esta tarea es tanto más urgente si se termina atribuyendo al fiscal la instrucción de los procesos penales, medida que, desde la propia Fiscalía General del Estado se estima como "de necesario establecimiento"60.

Quizá el primer paso para avanzar hacia la independencia del Ministerio Fiscal debería ser confiar la propuesta de nombramiento del Fiscal General del Estado a una mayoría parlamentaria -y no al Gobierno, como ahora-, una vez oído el CGPJ -nombrado con criterios de idoneidad, y no como ahora.

Con carácter general, es indispensable dotar a la justicia penal de medios idóneos proporcionales a la amenaza que representa la corrupción. Más y más especializados jueces ${ }^{61}$, más peritos experimentados, más policía judicial formada ad hoc, más recursos para la Fiscalía Anticorrupción y más cooperación entre las instituciones ${ }^{62}$, porque resulta obvio que mientras los corruptos cuenten, para eludir la acción de la justicia, con más y mejores medios de los que tiene el sistema público para perseguirlos, la batalla puede darse por definitivamente perdida.

Es igualmente indispensable reforzar la cooperación institucional, según el modelo de la Agencia Española de Administración Tributaria, la única institución que impone a sus funcionarios "un concreto deber de colaboración amplia" con jueces y fiscales. Otras entidades, como el Tribunal de Cuentas, el Servicio Ejecutivo de la Comisión

57 Neira Pena, A. M., "Colaboración público-privada como estrategia para combatir la corrupción: el sistema de responsabilidad penal de las personas jurídicas y los programas de prevención delictiva", cit., p. 123.

58 Ferrandis Ciprián, D., y Teruel García, I., “Corrupción y administración de justicia: una propuesta de reforma", en Jareño Leal, A. (dir.), Corrupción pública: cuestiones de política criminal (I), lustel, Madrid, 2014, pp. 75-77.

59 González-Cuéllar Serrano, N., “Halcones y palomas: la persecución penal de la corrupción y de la delincuencia económica", en Demetrio Crespo, E., y González-Cuéllar Serrano, N. (dir.), Halcones y palomas: corrupción y delincuencia económica, Castillo de Luna. Ediciones Jurídicas, Madrid, 2015, p. 521.

60 Fiscalía General del Estado, Memoria 2018, cit., p. 523.

61 Roma Valdés, A., "La persecución de los delitos de corrupción. Las dificultades de la cooperación internacional en los paraísos fiscales", cit., p. 49.

62 Ramírez Barbosa, P.A., "La Ley contra las prácticas corruptas en el extranjero. La FCPA de Estados Unidos: "Compliance", extraterritorialidad y responsabilidad de la persona jurídica. Reflexiones acerca del caso Odebrecht", cit., p. 39. 
de Prevención del Blanqueo de Capitales e Infracciones Monetarias, la Tesorería General de la Seguridad Social, el Banco de España o la Comisión Nacional de los Mercados y la Competencia proporcionan información a la Fiscalía Anticorrupción, y/0 aportan funcionarios en auxilio de jueces con escasa formación económica o contable. Especialmente remarcable es la puesta en marcha, en 2016, del Fichero de Titularidades Financieras, a cuyos datos tienen acceso directo la Agencia Española de Administración Tributaria y el Ministerio Fiscal, y de la Oficina de Recuperación y Gestión de Activos, que colabora con la Fiscalía Anticorrupción y los Juzgados en la identificación, gestión y realización de los efectos y ganancias del delito, incluso de los radicados fuera del territorio nacional, así como en el intercambio de información con oficinas análogas en el ámbito internacional ${ }^{63}$.

En cualquier caso, no se trata solo de completar organigramas con integración formal de instituciones, sino de implementar la cooperación de agencias realmente comprometidas en la anti-corrupción: DEFEX, uno de los ejemplos más clamorosos de corrupción política y criminalidad económica supranacional organizada en España, era una empresa -disuelta en 2017- dedicada a la venta de armamento, cuyo accionariado se repartía entre una entidad pública, la Sociedad Española de Participaciones Industriales en un $51 \%$, y empresas privadas, algunas de las cuales, caso de Maxamcorp Holding Assets (12\%) y Expal Systems (8\%), tienen sus matrices domiciliadas en EEUU. Pues bien, en el consejo de administración de DEFEX, por su condición de entidad empresarial pública, estaban representados el Ministerio de Asuntos Exteriores y Cooperación, el de Defensa, la Agencia Tributaria, dependiente del Ministerio de Hacienda, y el Servicio Ejecutivo de la Comisión de Prevención del Blanqueo de Capitales e Infracciones Monetarias, dependiente del Ministerio de Economía, que sin embargo no resultaron alarmados por movimientos ilícitos de armas y capitales, entre 2005 y 2014. Tan solo en marzo de 2019 un juez de la Audiencia Nacional ha dictado auto de procedimiento abreviado -similar al procesamiento en un sumario-, por, entre otros delitos, corrupción en las transacciones internacionales ${ }^{64}$.

La referencia al ámbito internacional es oportuna, porque la respuesta jurisdiccional a los affaires de corrupción política más graves ha de ser supranacional, superando los tradicionales obstáculos que a la eficacia en la persecución de estos delitos ha colocado la reivindicación del espacio criminal como coto exclusivo de la soberanía nacional. Si una de las reglas de oro de la globalización es la libre circulación de capitales, carece

63 Fiscalía General del Estado, Memoria 2018, cit., pp. 529-530.

64 https://www.abc.es/espana/abci-juez-procesa-empresa-publica-defex-irregularidades-ventaarmas-arabia-saudi-201903071048 _ noticia.html. Consulta: 25.04.2019. 
de argumentos justificantes la pretensión de elevar interesadas barreras fronterizas a la persecución penal de quienes delinquen aprovechando precisamente las facilidades que brinda la deslocalización de actividades, de centros de imputación personal y de beneficios. Hay que concluir, pues, reivindicando la definitiva instauración del principio de jurisdicción universal, hoy prácticamente barrido del ordenamiento español ${ }^{65}$ y sustituido en la materia por el principio de personalidad activa (Ley Orgánica del Poder Judicial, art. 23.4.n), tal como ratifica la Sentencia del Tribunal Supremo, Sala de lo Penal, sección 1a , 178/2019, de 02.04.2019.

Es igualmente necesario profundizar en la cooperación internacional, formalizada en una pléyade de instrumentos legales supranacionales ${ }^{66}$, y tan enfatizada por la Convención de las Naciones Unidas contra la corrupción (Nueva York, 31.10.2003), conocida como Convención de Mérida ${ }^{67}$, aunque también es cierto que, por tratarse de cuestión en que se solapa lo político-criminal con lo político lato sensu, los avances son más que limitados.

El dato que evidencia la solidez de las raíces económico-políticas del lavado de activos, que introduce en los circuitos normalizados el dinero proveniente de la corrupción política, es el de la capacidad de resiliencia del secreto bancario y la irreductibilidad de los paraísos fiscales. Cierto que la presión de organizaciones como el Grupo de Acción Financiera Internacional, ha ampliado los intercambios de información transfronteriza ${ }^{68}$, y cierto que algunos Estados han incrementado el control de las entidades financieras (Caso Banco ING, en Holanda e Italia ${ }^{69}$ ), pero los resultados obtenidos en la lucha contra el lavado de activos procedentes de la corrupción son cuantitativamente despreciables.

No puede ser de otro modo. La UE ha actualizado, el 10.10.2019, la lista negra de paraísos fiscales, que incluye nueve países: Belice, Fiji, Islas Vírgenes de los Estados Unidos, Omán, Samoa, Samoa Americana, Trinidad y Tobago y Vanuatu ${ }^{70}$. Pero los paraísos fiscales siguen dando cobijo a más de ocho billones de dólares, y en Delaware,

65 Muñoz Conde, F., y García Arán, M., Derecho Penal. Parte General, ga ed., Tirant lo Blanch, Valencia, 2015, p. 174.

66 JapIAssú, C. E., "La corruption dans un monde globalisé", en CÉRÉ, J.P. y JAPIASSÚ, C. E., (dir.), Corruption et Droit penal, L.'Harmattan. Paris,2019, pp. 23-25.

67 Argandoña, A., "The United Nations Convention against Corruption and its impact on international companies", en IESE Business School, Working Paper, 2006 (656), p. 8.

68 Fiscalía General Del Estado, Memoria 2018, cit., pp. 528-529.

69 https://www.eldiario.es/economia/Italia-ING-clientes-deficiencias_ 0 _ 879112751.html Consulta: 25.04.2019.

70 https://www.eldiario.es/economia/UE-Emiratos-Arabes-Unidos-Marshall_ 0 _951205274.html Consulta: 11.10.2019. 
ciudad norteamericana de menos de un millón de habitantes, están registradas 1.100.000 empresas de todo el mundo, el $42 \%$ de ellas (285.000) domiciliadas legalmente en el mismo edificio. En Delaware tienen domicilio legal el $59 \%$ de los bancos europeos que operan en USA, y en 2015 era el destino favorito de las empresas del IBEX 35 (índice de referencia de la bolsa española), que tienen allí 436 filiales ${ }^{71}$.

Una propuesta a meditar es la de implementar vías que permitan a la Corte Penal Internacional acceder al enjuiciamiento y castigo de la corrupción, al menos en su forma de delitos de "gran corrupción"72. Para ello, propone Hava, una estrategia de "lateral thinking", que prescinde del objetivo (inalcanzable) de tipificar una modalidad de corrupción subsumible en los requisitos del Estatuto de Roma, y que se centra en evitar su impunidad, a través de la identificación y toma en consideración de indicadores inequívocos de gran corrupción relevantes en dos fases clave del enjuiciamiento: en la investigación de los hechos y en la individualización de la pena. La regulación de estas fases en el Estatuto de Roma permite dar acogida a los elementos caracterizadores de la gran corrupción para habilitar la admisión a trámite de enjuiciamiento y condena de tales crímenes internacionales ${ }^{73}$.

El Ministerio Fiscal español reivindica también la mejora de los cauces no institucionales de detección de la corrupción, incentivando la colaboración de quienes (Wistleblowers) han participado en el delito ${ }^{74}$. Pero el Derecho penal español adolece, al respecto, de incoherencia. Así, en los delitos de malversación, la reparación del perjuicio patrimonial o la colaboración con las autoridades, aportando pruebas sobre hechos y responsables, determinan la reducción de la pena en uno o dos grados (CPE art. 434). Se trata de una atenuación específica muy cualificada, cuya apreciación, además, no está limitada en el tiempo, al contrario de las atenuantes genéricas del art. 21, $4^{\mathrm{a}}$ y $5^{\mathrm{a}}$. Y si quien se lucra de esta minoración de la pena es el colaborador extraneus, puede añadir otra: la prevista en el art. 65.3, lo que lleva a la práctica impunidad de quien intervino en episodios de corrupción muy graves. Este alcance despenalizador no puede ser valorado positivamente ${ }^{75}$.

71 https://www.elperiodico.com/es/economia/20170420/empresas-ibex-suman-969-filiales-enparaisos-fiscales-5983016 . Consulta: 25.04.2019.

72 Hava García, E., "Grand Corruption Strategies for Preventing International Impunity", en The Indonesian Journal of International \& Comparative Law, Cianjur, 2015 (II-3), pp. 488-489.

73 Ibid., pp. 505-519.

74 Fiscalía General del Estado, Memoria 2018, cit., p. 523.

75 Valejue Álvarez, I., "Malversación (arts. 432. 433, 434 y 435)", en González Cussac, J.L., (dir.) Comentarios a la reforma del Código Penal de 2015, 2ª ed., Tirant lo Blanch, Valencia, 2015, pp. 1215. 
A su vez, el art. 426, exime de pena por cohecho al particular que, habiendo accedido ocasionalmente a la solicitud de dádiva por parte del funcionario, lo denunciare antes de transcurridos dos meses y antes de la apertura del procedimiento. La generosa impunidad concedida al delincuente delator supone otra manifestación excesiva de Derecho premial.

Más allá de estos ejemplos, la regla general para incentivar la colaboración de los implicados en los delitos de corrupción debería ser la reducción proporcionada de la pena -que no su exención o práctica neutralización-, por colaboración activa -no por simple denuncia-, reproduciendo una opción político criminal ya presente en materia de narcotráfico (art. 376) o de organizaciones criminales (CPE, art. 570 quater 4).

Para incentivar la denuncia de sujetos ajenos al delito, hay que recurrir a otros medios. Que podrían llegar, incluso, a la remuneración de las denuncias realizadas por particulares, sobre el modelo de la False Claim Act en USA ${ }^{76}$. No hay consenso doctrinal, ni siquiera mayoría, que arrope argumentalmente este tipo de opciones; pero sí lo hay acerca de la necesidad de ofrecer al denunciante tutela, frente a posibles represalias por parte de acusados cuya impunidad se asienta precisamente en el silencio de quienes, sin participar en los hechos, los conocen. Máxime si, como ocurre frecuentemente en las administraciones públicas o en las estructuras empresariales, solo acceden a la notitia criminis los subordinados del delincuente, que pueden, además, resultar beneficiarios indirectos del delito ajeno ${ }^{77}$. Al respecto, la Convención de Naciones Unidas contra la Corrupción compromete a los Estados parte a considerar "la posibilidad de incorporar en su ordenamiento jurídico interno medidas apropiadas para proporcionar protección contra todo trato injustificado" al denunciante.

España, como advertía ya el Informe de la Comisión al Consejo y al Parlamento Europeo sobre lucha contra la corrupción en la UE, de 3.02.2014, no puede retrasar más la adopción de normas específicas protectoras de los denunciantes. En julio de 2018, la Comisión de Justicia del Congreso de los Diputados inició la tramitación de una Proposición de Ley integral de Lucha contra la Corrupción y Protección de los Denunciantes $^{78}$. La tramitación se ha paralizado, aunque parece inevitable la aprobación de una norma que incorpore el contenido de la Directiva (UE) del Parlamento Europeo

76 Nieto Martín, A., “De la Ética Pública al Public Compliance: sobre la prevención de la corrupción en las administraciones públicas", en Nieto Martín, A., y Maroto Calatayud, M., (dir.), Public Compliance. Prevención de la corrupción en administraciones públicas y partidos políticos, Universidad de CastillaLa Mancha, Cuenca, 2014, p. 29.

77 Kuduch, H., “Corrupción y proceso penal”, cit., p. 202.

78 https://www.europapress.es/nacional/noticia-gobierno-modificara-ley-proteccion-testigos-incluirdenunciantes-casos-corrupcion-20180711192433.html . Consulta: 25.04.2019. 
y del Consejo relativa a la protección de las personas que informen sobre infracciones del Derecho de la Unión (COM (2018) 0218), cuyo texto ha sido aprobado, en primera lectura, por el Parlamento el 16.04.201979.

\subsection{Control político.}

La imprescindible adaptación de las leyes penales, sustantivas, procesales y organizacionales, no garantiza la eficacia de los programas anticorrupción, y quizá como en ningún otro sector de la criminalidad, dada la capacidad de autoprotección y resiliencia de los sujetos implicados, la eficacia ha de buscarse extramuros del sistema penal. El núcleo de la lucha contra la corrupción pública se traslada de la política criminal stricto sensu al control político, por parte de la ciudadanía -primera interesada en ejercerlo-, y al administrativo, mediante instrumentos de seguimiento e inspección de la gestión pública que la hagan más transparente ${ }^{80}$. Y todo ello con el objetivo preferente de poner coto a la "incontrolable discrecionalidad" en la administración de lo público81

Quizá el primero de los instrumentos de saneamiento pudiera radicar en la implementación de programas de compliance en el seno de las instituciones públicas ${ }^{82}$.

Tal como, en opinión de Nieto, refleja la italiana Legge anticorrupzione $n$. 190/201233, "a los efectos de prevenir la corrupción, la Administración puede concebirse como una gran empresa", por lo que no deben existir diferencias entre los programas de cumplimiento empresariales y los públicos ${ }^{84}$.

Advierten estas propuestas que la normativa de carácter general (por ejemplo, en materia de urbanismo, de contratación o de subvenciones públicas) no es suficiente, lo que debería obligar a las administraciones a avanzar más en el diseño de controles internos, para los sectores en que más frecuentemente se manifiestan la arbitrariedad y la corrupción, poniendo en marcha comités de ética y centros autonómicos y locales de concreción y ejecución de las políticas anticorrupción impulsadas por agencias

79 http://www.europarl.europa.eu/sides/getDoc.do?pubRef=-//EP//TEXT+TA+P8-TA-20190366+0+DOC+XML+V0//ES\#def_2_ 1. Consulta: 25.04.2019.

80 Muñoz Conde, F., Derecho Penal. Parte Especial, $20^{a}$ ed., Tirant lo Blanch, Valencia, 2015, p. 873.

81 Roma Valdés, A., "La persecución de los delitos de corrupción. Las dificultades de la cooperación internacional en los paraísos fiscales", cit., p. 43.

82 Corcor Bidasolo, M., "Problemas político-criminales de la corrupción en los negocios y compliance", en Gómez Martín, V., Montiel, J.P., y Satzger, H. (eds.), Estrategias penales y procesales de lucha contra la corrupción, Marcial Pons, Barcelona, 2018, p. 225.

83 Anterior a la vigente Legge n. 3/19, de 09.01.2019.

84 Nieto Martín, A., "De la Ética Pública al Public Compliance: sobre la prevención de la corrupción en las administraciones públicas", cit., pp. 18-20. 
34 Apuntes político-criminales en torno a la corrupción pública como delincuencia socioeconómica organizada.

El caso español - Juan M. Terradillos Basoco

internacionales -como la Oficina Europea de Lucha contra el Fraude (OLAF) - y nacionales. Podrían, incluso abrirse los cauces a la participación ciudadana, principal interesada en la transparencia y el control del aparato público $0^{85}$.

Sin embargo, no se logra vislumbrar qué ventajas podría aportar la clonación de programas de cumplimiento privados para encajarlos en la estructura de los sistemas públicos de control, ya conocidos y siempre susceptibles de desarrollo en los sistemas democráticos.

No se vislumbran ventajas, porque, en principio, los programas societarios de cumplimiento, al menos en el caso español, no han probado su eficacia. Han tenido, sí, dos efectos positivos: a) permiten eximir de responsabilidad criminal a la persona jurídica, y b) permiten a los jueces fundamentar la condena en un defecto de organización, y no en criterios de responsabilidad objetiva. Pero las dudas sobre si son efectivos para prevenir delitos no han sido despejadas ${ }^{86}$.

Por otra parte, los programas diseñados para ser aplicados en la actividad económica de los empresarios, guiados por el principio de máximo rendimiento, no pueden ser transferidos, sic et simpliciter, a las administraciones, guiadas por el objetivo de servicio público legalmente definido y sometidas al control político. Sería necesario imponer a estos programas un proceso de adecuación, tan sustancial que comportaría mudar su naturaleza de programas de compliance, para, en movimiento circular recurrente, convertirlos en controles de naturaleza pública, regidos por principios políticos y no por recetas de gobernanza.

En la dirección de implementar mecanismos de control, Transparencia Internacional propuso para España, en 2014, la adopción de medidas "drásticas y urgentes" dirigidas a eliminar la opacidad económica de los partidos políticos ${ }^{87}$. Es el mismo objetivo al que responde, en Colombia, la Ley 1864 de 2017, que procedió a una ambiciosa reforma del CP Colombiano, introduciendo una pluralidad de nuevos delitos -entre ellos los de financiación ilegal de campañas electorales (CP, artículos 396 a, 396b y 396c)- dirigidos a "proteger los mecanismos de participación democrática".

Los partidos políticos, que en los textos constitucionales aparecen como instrumento fundamental de conformación de la voluntad popular y de participación política, son garantes de transparencia y probidad en la gestión pública. Pero cuando se

85 Ibid., pp. 25-28.

86 Corcoy Bidasolo, M., "Problemas político-criminales de la corrupción en los negocios y compliance”, cit., p. 224.

87 http://webantigua.transparencia.org.es/partidos_politicos/nota _ ti _ contra _ corrupcion.pdf Consulta: 25.04.2019. 
ven afectados por el virus de la corrupción, también son sus propagadores activos y/o sus favorecidos cómplices ${ }^{88}$.

La pretensión político-criminal de intervenir en estos ámbitos está más que justificada. Los ejemplos de corrupción más llamativos tienen un denominador común: la dádiva se relaciona con el partido político de adscripción de la autoridad corrupta. Lo que no impide, sin embargo, que, en buen número de casos, termine en los bolsillos personales de esta y no en las opacas cuentas partidarias.

El partido, en efecto, recepta, directamente o por mano ajena, caudales con los que financiar campañas electorales, en las que los elegidos resultarán rehenes de sus donantes; se compromete a avalar parlamentariamente las propuestas de la autoridad política, que, por su parte, reintegrará a los co-militantes el precio -nunca completo- de su venta al mejor postor; o garantiza a sus líderes tanto la impunidad ante el Derecho punitivo como la garantía de goce pacífico de su injustificable enriquecimiento. Se consolida, así, una cohorte de presuntos servidores públicos que son en realidad palafreneros de intereses privados y que acceden a cuotas importantes de poder en su condición de miembros de un partido político o, al menos, con el apoyo de la organización $n^{89}$.

La opción española, atendiendo las recomendaciones de transparencia internacional, se plasmó en la LO 1/2015, que incorporó al CP los artículos 304 bis y 304 ter. La doctrina ha podido señalar, sin embargo, deficiencias a superar: se criminalizan donaciones, pero no otras conductas vinculadas a la financiación ilegal, como el falseamiento de cuentas o la doble contabilidad; el tipo básico solo prevé pena de multa, y en ningún caso se recurre a la inhabilitación especial; la descripción de los comportamientos delictivos se remite in totum a las infracciones de la $L O$ de Financiación de Partidos Políticos, con las dificultades aplicativas que esta técnica comporta; y no se tipifican modalidades de financiación equiparables en gravedad a las criminalizadas: es el caso de las condonaciones de créditos, de las donaciones ilegales de bienes inmuebles o de la financiación a través de fundaciones ${ }^{90}$.

En su informe de 2016 sobre corrupción, Transparencia Internacional también recomendaba a los países de la UE regular las actividades de lobbying y garantizar la

88 Terradillos Basoco, J.M., "Partidos políticos y corrupción política. Algunas estrategias políticocriminales", en Medina Cuenca, A. (coord..), Luces y sombras de la reforma penal y procesal en Iberoamérica. Libro Homenaje al profesor Dr. Ignacio F. Benítez Ortúzar, Unijuris, La Habana, 2017, p. 32.

89 Ibíd., p. 31.

90 Hava García, E., "Financiación ilegal de partidos políticos", en Terradillos Basoco, J.M. (coord.), Lecciones de Derecho Penal. Parte Especial, tomo IV, Editorial Jurídica Continental, San José (Costa Rica), 2017, pp. 14-15. 
transparencia de estos ${ }^{91}$. En el mismo año, el Fondo Monetario Internacional añadió la advertencia de que la transparencia es un prerrequisito indispensable, no solo del correcto funcionamiento del mercado sino también de las políticas anticorrupción ${ }^{92}$.

Tres años más tarde, el informe para 2019 del Corporate Europe Observatory denuncia que los Estados presentes en el Parlamento Europeo siguen siendo permeables a los grupos de presión empresariales, tal como se evidenció en la negociación del non nato, aunque recuperado en estos días, Tratado de Libre Comercio entre USA y UE, pero también en otros casos menores (roaming-Telefónica ${ }^{93}$, glifosatos ${ }^{94}$, Arias Cañete ${ }^{95}$ ), en los que, a ojos de la ciudadanía española, la presión sobre los parlamentarios ha ido dirigida a decisiones difícilmente compatibles con el interés general, y que, sin embargo, pueden llegar a ser decisiones válidas, por cuanto la definición del interés general compete a los parlamentarios presionados por el lobby ${ }^{96}$.

En marzo de 2017, el Congreso de los Diputados español aprobó una proposición de ley que preveía, atendiendo las indicaciones del Grupo de Estados contra la Corrupción (GRECO), la creación de un Registro Público obligatorio, en el que deberían constar los grupos de interés, las reuniones con diputados y la documentación intercambiada. Se trataba, pues, de un mero registro, que no incluía las reuniones con los senadores ni con los miembros del Gobierno, ni la "huella legislativa" o trazabilidad de las leyes, ni información económica sobre el lobby ${ }^{97}$.

Finalmente, hay que aludir a otra imprescindible reforma legal dirigida a terminar, a través del control político, con el fenómeno de las "puertas giratorias".

91 Ver http://transparencia.org.es/wp-content/uploads/2016/11/nota _ prensa _ barometro-2016.pdf. Consulta: 25.04.2019.

92 International Monetary Fund. Fiscal Affairs Dept, (2016), Corruption: Costs and Mitigating Strategies, pp. 4 y 17. En https://www.imf.org/en/Publications/Staff-Discussion-Notes/Issues/2016/12/31/ Corruption-Costs-and-Mitigating-Strategies-43888 . Consulta: 25.04.2019.

93 https://www.eldiario.es/economia/influencia-empresariales-decisiones-GobiernosUE_o_865114433.html. Consulta: 25.04.2019.

94 https://www.eldiario.es/sociedad/tejerina _ ${ }_{\text {_ }}$ 741926598.html . Consulta: 25.04.2019.

95 https://www.eldiario.es/economia/influencia-empresariales-decisiones-GobiernosUE___ 865114433.html. Consulta: 25.04.2019.

96 Cugat Mauri, M., La desviación del interés general y el tráfico de influencias, Cedecs, Barcelona, 1997, pp. 55-56.

97 Terradillos Basoco, J.M., "Corrupción política: consideraciones político-criminales", en Revista Electrónica de Estudios Penales y de la Seguridad, San José (Costa Rica), 2017 (1), pp. 13-14. En https://www.ejc-reeps.com/ . Consulta: 25.04.2019. 
Para evitar que quienes toman las decisiones políticas corran el riesgo de verse condicionados por intereses personales espurios vinculados a su previa dedicación o posterior paso al sector privado, los ordenamientos conocen leyes que regulan los conflictos de intereses de altos cargos y sus incompatibilidades: en España, la Ley 3/2015, de 30 de marzo, reguladora del ejercicio del alto cargo de la Administración General del Estado. En virtud de su art. 15.1 y 2, los altos cargos, durante los dos años subsiguientes a su cese, no podrán prestar servicios en entidades privadas que hayan resultado afectadas por sus decisiones o que hayan estado sujetas a su supervisión o regulación. Sin embargo, y como excepción a la regla, podrán reincorporarse a sus anteriores empresas, sin esa limitación temporal, quienes salieron de ellas para ocupar el cargo público, aunque esas empresas estuviesen relacionadas con sus competencias en cuanto tal, siempre que su incorporación lo sea en puestos de trabajo no "directamente" vinculados a dichas competencias (art. 15.4).

Los ex-altos cargos que, antes de transcurridos los dos años, deseen incorporarse a una actividad privada relacionada con el desempeño de su función pública, deberán solicitarlo a la Oficina de Conflictos de Intereses, creada en 2006. Pero no parece que la Oficina se haya mostrado demasiado estricta en su función de mantener los intereses públicos separados de los privados. A 11 de marzo de 2019 se habían expedido, desde 2006, 525 autorizaciones que permitieron la incorporación de 295 altos cargos del Estado a distintas empresas y ocupaciones ${ }^{98}$. Los datos muestran como las solicitudes se multiplicaron tras los cambios de Gobierno en diciembre de 2011 ( $4^{\circ}$ trimestre de 2011, 24) y junio de 2018 (4º trimestre de 2018, 37).

De entre las últimas solicitudes de compatibilidad respondidas favorablemente, destacan algunas vinculadas al último de estos cambios de gobierno. El líder del bufete de abogados por el que el 11.03.2019 fichó la que fuera, hasta 2018, vicepresidenta del Gobierno, fue condenado en 2015 por ocho delitos contra la Hacienda Pública: aceptó una pena de dos años de cárcel tras un pacto con la Fiscalía al que no se opuso la Abogacía del Estado -que entonces dependía de la Vicepresidencia del Gobierno. En la sentencia, se declaraba probado que la defraudación ascendió a 3,02 millones de euros ${ }^{100}$.

98 https://www.eldiario.es/economia/DATOS-Todas-autorizaciones-Gobiernotrabajar_ $0 \_$549795422.html. Consulta: 25.04.2019.

99 https://www.eldiario.es/economia/DATOS-Todas-autorizaciones-Gobiernotrabajar _ 0 _ 549795422.html. Consulta: 25.04.2019.

100 https://www.eldiario.es/catalunya/politica/Cuatrecasas-condenado-delitos-fiscalesFiscalia _ $0 \_$876662826.html. Consulta: 25.04.2019. 
El entonces responsable de la subsecretaría de Presidencia, a la que estaba adscrita la Abogacía del Estado, fue ascendido por el Banco Santander, a los once días de dejar el Gobierno, al cargo de secretario general y del consejo de la entidad ${ }^{101}$.

La firma de lobby Kreab, que cuenta en su nómina de personal con un buen número de consultores expolíticos de diferentes partidos, contrató a quien fuera secretario de Estado de Hacienda desde 2011 a 2016, como asesor en políticas financieras y "para liderar y consolidar la práctica de regulación financiera en España y con las directrices y normativa que desde la Unión Europea se propone en esta materia". La compañía también señala que se dedicará a "los asuntos públicos para la región de América Latina"102.

De hecho, las solicitudes de compatibilidad denegadas por la Oficina de Conflictos de Intereses no llegan a la decena ${ }^{103}$, de modo que las idas y venidas entre lo público y lo privado son la regla.

Por otra parte, las sanciones a los infractores (ocho en trece años) ${ }^{104}$ difícilmente pueden tener, por su extraordinaria lenidad, un efecto preventivo. Son, para las infracciones leves, amonestación; para las graves, declaración -con publicación en el Boletín Oficial del Estado- de incumplimiento de la Ley; para las muy graves, la misma declaración y, además, pérdida de la compensación económica pública por el cese y obligación de restituir lo indebidamente ingresado (ley 3/2015, artículos 25 y 26).

\section{Políticas económicas}

Las políticas que actúan en el plano penal, en el procesal, en el de control o en el de la transparencia, van dirigidas, sustancialmente, a evitar que el político, en cuanto servidor público titular -por delegación de sus administrados ${ }^{105}$ - de poderes que solo se legitiman en la medida en que sean ejercidos en pos de intereses colectivos legalmente definidos, los utilice en desmedro de su función originaria.

Son políticas imprescindibles, pero no suficientes. Si se ha aceptado que la corrupción es una modalidad de criminalidad económica, las políticas preventivas no

101 https://www.eldiario.es/economia/Recortes-renovables-Rajoy-beneficiaronSantamaria_ 0 _ 876663109.html. Consulta: 25.04.2019.

102 https://www.eldiario.es/economia/Kreab-exsecretario-Hacienda-Miguel-Ferre _ 0 _ 876663031. html. Consulta: 25.04.2019.

103 http://politica.elpais.com/politica/2017/04/11/actualidad/1491918937_808225.html . Consulta: 25.04.2019.

104 http://politica.elpais.com/politica/2017/04/11/actualidad/1491918937_808225.html . Consulta: 25.04.2019.

105 Muñoz Conde, F., Derecho Penal. Parte Especial, cit., p. 871. 
pueden limitarse a actuar sobre los instrumentos que manejan corruptores y corruptos; han de hacerlo también sobre el modelo económico que impulsa su utilización espuria. Y no hacerlo es tanto como asumir el obsecuente papel de cómplice.

Aludiremos a algunos de los elementos de ese modelo.

Situaciones como la ejemplificada por el "caso Odebrecht", que, sin embargo, no es sino reproducción de las protagonizadas por grandes corporaciones a lo largo de la crisis económica que se desencadenó, a nivel mundial, a partir de septiembre de 2008, ponen de relieve que el diseño científico de estrategias político-criminales frente a la corrupción ha de enmarcarse en su contexto político-económico actual; esto es, en el proceso de expansión transnacional de la economía de mercado que conocemos como globalización.

La desregulación característica de la globalización económica es el caldo de cultivo que garantiza la prevalencia de los intereses particulares sobre las políticas públicas. En efecto, allí donde no se regula la economía lícita, no se regula la ilícita, de modo que se facilitan los movimientos de la gran criminalidad económica, que actúa a un lado y al otro de la difusa frontera que separa lo permitido exitoso de lo delictivo. Lo que, además, resulta coherente con un entorno en el que los criterios de funcionalidad han sustituido las políticas públicas por la gobernanza de estrategias económicas ${ }^{106}$, y en el que el criterio determinante de lo que debe ser prohibido no es su dañosidad, sino su disfuncionalidad para con el mercado.

De ahí que el primer paso de una lucha anticorrupción coherente sea el fortalecimiento del control político sobre la actividad económica, una vez que se sabe que la lex mercatoria, cuando su única regla es la obtención del máximo beneficio, no se comporta como un principio de asignación eficiente de recursos, sino como la ley de la selva, en la que el pez grande -el que mejor compite- termina comiéndose al pez chico -el perdedor disfuncional. Sobre todo, si el mejor competidor lo es porque cuenta con la anuencia de servidores públicos que abdican de sus cometidos constitucionales.

De otra parte, la funcionalidad al mercado fija las tasas de tolerancia frente a la corrupción asumibles por el sistema.

Así resulta particularmente visible en ciertos ámbitos, como el de la delincuencia ambiental ${ }^{107}$, del trabajo irregular ${ }^{108} 0$ del fraude fiscal. Nos detendremos en este.

106 BelL, E., Criminal Justice and Neoliberalism, Basingstoke, 2011, p. 17.

107 Sánchez Zapata, S.F., "La protección penal del medio ambiente: análisis del art. 338 del CP Colombiano sobre minería ilegal", en Actualidad Jurídica Ambiental, 2014 (31), pp. 6-7.

108 RAnDSTAD, Informe anual sobre la flexibilidad laboral y el empleo. 2014. En http://www.randstad.es/ tendencias360/informe-flexibilidad-en-el-trabajo-randstad-2014 . Consulta: 25.04.2019. 
40 Apuntes político-criminales en torno a la corrupción pública como delincuencia socioeconómica organizada.

El caso español - Juan M. Terradillos Basoco

Mientras las leyes penales de todos los países de nuestro círculo de cultura tipifican -aunque también abren puertas a la impunidad ${ }^{109}$ - las formas más graves de delito fiscal, los defraudadores españoles nutren a los paraísos fiscales, según el National Bureau of Economic Research (USA), con 140.000 millones de euros, el 12\% del PIB de España. $Y$, sin embargo, se estima que, con de un plan de lucha contra el fraude fiscal realista y eficiente, se podrían recaudar a medio plazo hasta 40.000 millones de euros ${ }^{110}$.

No parece creíble, a la vista de la inexistencia de ese plan eficiente, que el fraude fiscal, tantas veces vinculado a la corrupción de los funcionaros y autoridades encargados de perseguirlo, esté a punto de ser controlado. Pero resulta obvio que no podrán registrarse avances mientras solo actúe la puramente simbólica norma penal, renunciando al control efectivo de los marcos de actuación de las entidades bancarias. Solo un dato: el primer banco español ocupa el primer lugar, entre las empresas del IBEX 35, por el número de sucursales en paraísos fiscales: 216111. Sin una decidida voluntad política de impedir a las entidades financieras la realización de operaciones en ámbitos de ilicitud, el fraude fiscal y el lavado de activos, tantas veces vinculados a la corrupción, no pueden ser eficazmente controlados ${ }^{112}$.

La impunidad en la materia viene reforzada por las regularizaciones fiscales, que, presentes con un nombre u otro en buena parte de los ordenamientos estatales, constituyen manifestación de un derecho de gracia encubierto que privilegia y empodera a los defraudadores. En España, el Real Decreto-Ley 12/2012, que no es pieza única en Derecho comparado (Argentina ${ }^{113}$, Brasil ${ }^{114}$, Perú115, etc.), ni en la reciente historia penal española -hubo amnistías fiscales, de dudosa constitucionalidad en 1984 y en $1991^{116}$-premió a los grandes infractores, permitiéndoles regularizar los capitales

109 González Agudelo, G., “Defraudación tributaria”, en Terradillos Basoco, J.M. (coord.), Lecciones de Derecho Penal. Parte Especial. Derecho Penal Económico, tomo V, Editorial Jurídica Continental, San José (Costa Rica), 2017, pp. 268-270.

110 http://www.eleconomista.es/economia/noticias/8918149/02/18/Tecnicos-de-hacienda-ven-pocoalentador-que-la-ue-desclasifique-a-panama-como-paraiso-fiscal.html . Consulta: 25.04.2019.

111 Ver, supra, nota 59

112 Terradillos Basoco, J.M., “Corrupción, globalización y Derecho Penal Económico”, cit., pp. 41-42.

113 http://lta.reuters.com/article/businessNews/idLTAKBN14G1MT . Consulta: 25.04.2019.

114 http://www.expansion.com/latinoamerica/2016/11/01/5818bc2be2704e685c8b45ef.html Consulta: 25.04.2019.

115 http://www.fundssociety.com/es/noticias/normativa/peru-se-une-a-la-ola-de-amnistias-fiscalesen-america-latina . Consulta: 25.04.2019.

116 Aвel Souto, M. "El blanqueo de dinero: problemática actual española, con anotaciones de Derecho comparado estadounidense", en Demetrio Crespo, E., y González-Cuéllar Serrano, N. (dir.), Halcones 
evadidos y gravando la operación con un tipo impositivo (10\%, que, en la práctica se convirtió en un 2\%) muy inferior al general: no solo se les otorgó inmunidad penal, también disfrutaron un tratamiento fiscal de favor ${ }^{117}$. El TC español, en sentencia de 08.06.2017, anularía la amnistía fiscal por haber sido aprobada mediante decreto-ley, pero no cuestionó la validez de las regularizaciones ya producidas.

Criminalidad económica y corrupción política van juntas. En efecto, cuando el Estado Social de Derecho asume la defensa de los valores que lo legitiman y ejerce el liderazgo político, intensificando la supervisión de los procesos económicos, los mercados buscan la desregulación fáctica a través de la corrupción, que, con independencia de lo que disponga la legalidad, crea limbos de "ajuridicidad" que les devolverán el control de la economía118.

En el plano internacional, el procedimiento es conocido: en el mercado mundializado, las metrópolis transfieren a los entornos periféricos más débiles riesgos -p. ej., ambientales o financieros- y extorsión social -p. ej., degradación laboral o sindical. Pero la transferencia solo será exitosa en la medida en que la asuma e imponga un poder autóctono, incentivado, a su vez, por los exportadores de riesgos. Ese poder autóctono se ve obligado a ocultar su carencia de legitimidad y a acallar a sus detractores mediante estrategias de contrainsurgencia, apoyadas por la metrópoli. Así, el poder de las autoridades corruptas y el enriquecimiento de los corruptores se necesitan y potencian recíprocamente ${ }^{119}$.

La corrupción se generaliza cuando es arropada por un entorno cultural e ideológico en el que la dádiva al funcionario se considera como retribución adecuada y eficiente ${ }^{120}$. Esta perversión ideológica viene avalada por sectores de la doctrina penal que se han prestado a avalar la impunidad de la corrupción generalizada.

Por ejemplo, incorporando al argumentario la fuerza destipificante de la adecuación social, reivindicando la aplicación ultra vires del principio de intervención mínima 0 apelando a razones de no exigibilidad de otra conducta. Así, se arguye que:

y palomas: corrupción y delincuencia económica, Castillo de Luna. Ediciones Jurídicas, Madrid, 2015, pp. 158-159.

117 Terradillos Basoco, J.M., "Cuatro décadas de política criminal en materia socioeconómica", en Demetrio Crespo, E. (dir.), Crisis financiera y Derecho Penal Económico, Edisofer-BdeF, Madrid, 2014, pp. 62-63.

118 Ibíd., pp. 49 y 67.

119 Ibíd., p. 68.

120 García López, E., "La corrupción ¿Un problema jurídico o un estadio sociológico-moral?", en El Cronista del Estado Social y Democrático de Derecho, Madrid, 2014 (35), p. 69. 
42 Apuntes político-criminales en torno a la corrupción pública como delincuencia socioeconómica organizada.

El caso español - Juan M. Terradillos Basoco

La misión del Derecho Penal no es cambiar los términos de lo socialmente adecuado, sino proteger el statu quo. Por eso la adecuación social es una causa de exclusión de la tipicidad. Sin embargo, en los casos de corrupción internacional precisamente hay que contar con que la ley local permite 0 tolere la existencia de pagos a los funcionarios 0 , sencillamente se vea superada por una costumbre en este sentido. Cuando el entorno se muestra absolutamente proclive a la corrupción -cuando la confusión se halla institucionalizada- la utilización del Derecho penal como mecanismo de cambio incurre en el denostado Derecho penal promocional.......en efecto, el Derecho penal no debe definir las posiciones sociales y jurídicas. Debe limitarse a su protección... en entornos estructuralmente corrompidos, la pregunta abierta es si acaso resulta exigible a un agente económico abstenerse de entrar en el juego. La respuesta -se concluye- debería ser probablemente negativa. ${ }^{121}$

Estas tesis desconocen que, si bien es cierto que al Derecho penal no le corresponden funciones promocionales, sí está obligado a superar, en la medida de sus escasas posibilidades, los obstáculos a la efectiva vigencia de los principios constitucionales y de los derechos humanos propios del Estado Social de Derecho. Entre estos obstáculos ocupa un lugar preferente la corrupción.

Estas tesis incurren igualmente en mistificación cuando afirman que la función del Derecho penal no es cambiar la sociedad sino "proteger el statu quo", no "definir posiciones sociales o jurídicas", sino protegerlas. El conservadurismo que se reivindica, pretende desconocer que el principio de lesividad obliga a la tutela de bienes jurídicos esenciales, las más de las veces identificados con derechos civiles, políticos, económicos, sociales y culturales de primer nivel, por más que esa tutela suponga romper con un statu quo, incluso consuetudinario, en el que los detentadores del poder se lucren ignorándolos.

\section{Epílogo}

La lucha contra la corrupción está condenada al fracaso si no se corresponde con una conciencia social identificada con los valores democráticos y decidida a castigar electoralmente a los candidatos políticos corruptos o corruptores. Pero los valores políticos democráticos no pueden arraigar allí donde prevalecen otros, contrapuestos, vinculados a la globalización neoliberal, que "elimina del terreno de juego los bienes públicos y comunes, la intervención pública y la política social"122.

121 Silva Sánchez, J. M., "Doce tesis sobre el delito de corrupción de funcionarios del art. 286 ter CP español", en Gómez Martín, V., Montiel, J.P., y Satzger, H. (eds.), Estrategias penales y procesales de lucha contra la corrupción, Marcial Pons, Barcelona, 2018, pp.64-65.

122 Vicente Giménez, T., y Berzosa Alonso Martínez, C., "El triunfo de las finanzas capitalistas y el deterioro de los derechos sociales y de los derechos ecológicos", en Jueces para la Democracia, Madrid, 2014 (80), p. 20. 
En ese contexto, la lucha penal anticorrupción no puede ser ni invasiva ni exitosa: en 2018 los juzgados españoles concluyeron cuarenta y ocho procedimientos por corrupción, con juicio oral o procesamiento para doscientas cinco personas. Se dictaron sesenta y tres sentencias, de las cuáles cuarenta -un sesenta y tres por ciento del total- condenatorias ${ }^{123}$. A 1.01.2019 contamos con ciento diez y siete presos por corrupción ${ }^{124}$.

La pobreza de las cifras se corresponde con los parámetros de la realidad económica globalizada, escorada vocacionalmente hacia la inhibición en materia de principios políticos, valores constitucionales y derechos sociales, que dibuja un panorama ideológico tolerante con la supeditación de lo público-colectivo a lo económico-privado y proclive a la corrupción, y que pone a la política criminal ante una disyuntiva radical: 0 amigable vecindad con la corrupción o intervención frente a los factores criminógenos de la estructura económica y política

Se trata de la consecuencia inevitable de constatar que la corrupción, en cuanto delito, tipificado o tipificable, es un problema jurídico y político-criminal; pero, en cuanto destrucción de la ética colectiva ${ }^{125}$, es un problema político-social que refleja la degradación de una sociedad que no cree en los valores que retóricamente proclama. La respuesta a la corrupción, en este nivel, "exige recuperar lo que todavía está vivo de nuestro sistema de legitimidad y servirse de ello para recobrar los valores de la democracia mediante el expediente de podar lo que está muerto" ${ }^{126 .}$

\section{Bibliografía}

AвEL SOUto, M. "El blanqueo de dinero: problemática actual española, con anotaciones de derecho comparado estadounidense", en Demetrio Crespo, E., y González-Cuéllar Serrano, N. (dir.), Halcones y palomas: corrupción y delincuencia económica, Castillo de Luna. Ediciones Jurídicas, Madrid, 2015, pp. 101-177.

Acale Sánchez, M., "Delitos contra la administración pública (II)", en Terradillos Basoco, J.M. (coord.), Lecciones de derecho penal. Parte especial, tomo IV, Editorial Jurídica Continental, San José (Costa Rica), 2016, pp. 247-297.

Álvarez García, F.J., "Las prioridades de la justicia criminal", en Álvarez García, F.J., (dir.), Estudio crítico sobre el anteproyecto de reforma penal de 2012, Tirant Lo Blanch, Valencia, 2013, pp.25-47.

123 https://www.iustel.com/diario_del_derecho/noticia.asp?ref_iustel=1186865\&utm source=DD\&utm _ medium=email\&nl=1\&utm _ campaign=25/3/2019 . Consulta: 25.04.2019.

124 http://www.poderjudicial.es/cgpj/es/Temas/Transparencia/Repositorio-de-datos-sobre-procesospor-corrupcion . Consulta: 25.04.2019. Ver, supra, nota 51.

125 Castro Cuenca, C. G., "Derecho penal y lucha contra la corrupción en el siglo XXI", cit., pp. 290-291.

126 García López, E., "La corrupción ¿Un problema jurídico o un estadio sociológico-moral?", cit., p. 74. 
44 Apuntes político-criminales en torno a la corrupción pública como delincuencia socioeconómica organizada.

El caso español - Juan M. Terradillos Basoco

ArgandoñA, A., "The United Nations Convention Against Corruption And Its Impact On International Companies", en IESE Business School. Working Paper, 2006 (656), pp. 1-20.

BeLL, E., Criminal justice and neoliberalism, Basingstoke, 2011.

Berdugo Gómez de la Torre, I., “Corrupción y derecho penal, condicionantes internacionales y reformas del código penal", en Demetrio Crespo, E., y González-Cuéllar Serrano, N. (dir.), Halcones y palomas: corrupción y delincuencia económica, Castillo de Luna. Ediciones Jurídicas, Madrid, 2015, pp. 53-99.

Capella, J-R., "Contra la judicialización de la política", en mientras tanto.e, 2006 (42), Barcelona. En http://www.mientrastanto.org/boletin-42/notas/contra-lajudicializacion-de-la-politica. Consulta: 25.04.2019.

Castro Cuenca, C. G., “Derecho penal y lucha contra la corrupción en el siglo XXI”, en Ramírez Barbosa, P.A., (dir.), Desafíos del Derecho penal en la sociedad del siglo XXI. Libro Homenaje a Ignacio Berdugo Gómez de la Torre, Temis, Bogotá, 2018, pp. 263-298.

Corcoy Bidasolo, M., "Problemas político-criminales de la corrupción en los negocios y compliance", en Gómez Martín, V., Montiel, J.P., y Satzger, H. (eds.), Estrategias penales y procesales de lucha contra la corrupción, Marcial Pons, Barcelona, 2018, pp. 213-226.

Cugat Mauri, M., La desviación del interés general y el tráfico de influencias, CEDECS, Barcelona, 1997.

De Cervantes Saavedra, M., El ingenioso hidalgo don Quijote de la Mancha, edición digital basada en la de ediciones de la lectura, Madrid, 1911-1913, segunda parte, capítulo xxxii. En http://www.cervantesvirtual.com/obra-visor/el-ingenioso-hidalgo-donquijote-de-la-mancha-6/html/05f86699-4b53-4d9b-8ab8-b40ab63fb0b3_16. html\#i_119_. Consulta: 25.04.2019.

De Cervantes Saavedra, M., El ingenioso hidalgo don Quijote de la Mancha, edición digital basada en la de ediciones de la lectura, Madrid, 1911-1913, segunda parte, capítulo xxxvi. En http://www.cervantesvirtual.com/obra-visor/el-ingenioso-hidalgo-donquijote-de-la-mancha-6/html/05f86699-4b53-4d9b-8ab8-b40ab63fb0b3_17. html\#i_125_. Consulta: 25.04.2019.

De La Cuesta Arzamend, J. L., "La corruption: réponses internationales et européennes à un phénomène nécessitant une politique criminelle intégrale", en Céré, J.P. y Japiassú, C. E., (dir.), Corruption et droit penal, L.'Harmattan. Paris, 2019, pp. 141-163.

De La Mata Barranco, N.J, La respuesta a la corrupción pública. Tratamiento penal de la conducta de los particulares que contribuyen a ella, Comares, Granada, 2004. 
De la Mata Barranco, N.J., "El decomiso ide los bienes del delito?", en Almacén de derecho, 18.11.2016. En https://almacendederecho.org/decomiso-los-bienesdel-delito/. Consulta: 25.04.2019.

Dolz LAGo, M. J., "Los decomisos: aproximación a sus aspectos sustantivos y procesales tras las reformas del 2015 (1)", en La ley penal, Madrid, 2017 (124), pp. 1-25.

Ferrandis Ciprián, D., y Teruel García, I., “Corrupción y administración de justicia: una propuesta de reforma", en Jareño Leal, A. (dir.), Corrupción pública: cuestiones de política criminal (I), lustel, Madrid, 2014, pp. 63-87.

FEREJOHN, J., "Judicializing politics, politicizing law", en Law and contemporary problems, 2002 (65), Durham, pp. 41-68 en http://scholarship.law.duke.edu/lcp/vol65/iss3/3 . Consulta: 25.04.2019.

Fiscalía General del Estado, Memoria 2018. En https://www.fiscal.es/fiscal/ pa_webapp_sgntj_nfis/descarga/memoria2018_fiscalia_anticorrupcion. pdf?ldfile =b694282b-c7f6-4af4-8116-f5a437beaa5b. Consulta: 25.04.2019.

Galeano, E., Patas arriba. La escuela del mundo al revés, $1^{\text {a }}$ edic., Catálogos, Buenos Aires, 2006.

García López, E., "La corrupción ¿un problema jurídico o un estadio sociológico-moral?", en El cronista del Estado Social y Democrático de Derecho, Madrid, 2014 (35), pp. 68-74.

Gııı, G.A., Cómo se investiga. Guía de investigación social para no especialistas, Avance, Barcelona, 1971.

Gimeno Bevì̀, J., "Algunos problemas procesales en la recuperación de activos"; en Nieto Martín, A., y Maroto Calatayud, M., (dir.), Public compliance. Prevención de la corrupción en administraciones públicas y partidos políticos, Universidad de Castilla-La Mancha, Cuenca, 2014, pp. 279-302.

González Agudelo, G., "Defraudación tributaria", en Terradillos Basoco, J.M. (coord.), Lecciones de derecho penal. Parte especial. Derecho penal económico, tomo V, Editorial Jurídica Continental, San José (Costa Rica), 2017, pp. 253-276.

González-Cuéllar Serrano, N., "Halcones y palomas: la persecución penal de la corrupción y de la delincuencia económica”, en Demetrio Crespo, E., y González-Cuéllar Serrano, N. (dir.), Halcones y palomas: corrupción y delincuencia económica, Castillo de Luna. Ediciones Jurídicas, Madrid, 2015, pp. 507-542.

Grupo de Estudios de Política Criminal, una alternativa a algunas previsiones penales utilitarias. Indulto, prescripción, dilaciones indebidas y conformidad procesal, Tirant Lo Blanch, Valencia, 2014. En http://www.gepc.es/web/sites/default/files/ ficheros/libro15_0.pdf. Consulta: 25.04.2019. 
46 Apuntes político-criminales en torno a la corrupción pública como delincuencia socioeconómica organizada.

El caso español - Juan M. Terradillos Basoco

Hava GarcíA, E., "Grand corruption strategies for preventing international impunity", en The indonesian journal of international \& comparative law, Cianjur, 2015 (II-3), pp. 481-521.

Hava García, E., "Financiación ilegal de partidos políticos", en Terradillos Basoco, J.M. (coord.), Lecciones de derecho penal. Parte especial, tomo IV, Editorial Jurídica Continental, San José (Costa Rica), 2017, pp. 13-30.

International Monetary Fund. Fiscal Affalis Dept., (2016), Corruption: costs and mitigating strategies, pp. 1-43. En https://www.imf.org/en/publications/staff-discussionnotes/issues/2016/12/31/corruption-costs-and-mitigating-strategies-43888. Consulta: 25.04.2019.

JaPiAssú, C. E., "La corruption dans un monde globalisé", en Céré, J.P. y Japiassú, C. E., (dir.), Corruption et droit penal, L.'Harmattan. Paris,2019, pp. 15-26.

Jareño Leal, A., "La corrupción en la contratación pública", en Pasajes. Revista de pensamiento contemporáneo, 2013 (42), pp. 14-21. En http://roderic.uv.es/bitstream/ handle/10550/45549/14-21. pdf?Sequence =1 fisallowed=y . Consulta: 25.04.2019.

Jiménez VillareJo, C.06), “Contra la corrupción: más trasparencia, más prevención”, en Revista de la Facultad de derecho de la Universidad de Granada, 2006 (9), pp. 531-551.

KudıcH, H., “Corrupción y proceso penal”, en Gómez Martín, V., Montiel, J.P., y Satzger, H. (eds.), Estrategias penales y procesales de lucha contra la corrupción, Marcial Pons, Barcelona, 2018, pp. 195-209.

LABORDE, D. M., "Interfaz entre corrupción pública transnacional y derechos humanos. Respuesta penal integrada", en Ramírez Barbosa, P.A., (dir.), Desafíos del derecho penal en la sociedad del siglo xxi. Libro homenaje a Ignacio Berdugo Gómez de la Torre, Temis, Bogotá, 2018, pp. 211-234.

Medina Salas, M.A., "Consideraciones sobre la inconstitucionalidad del delito de enriquecimiento ilícito", en Capítulo Criminológico, Maracaibo, 2009 (37-1), pp. 133-152.

MeINI, I., Delitos contra la Administración Pública, USAID, ciudad de Guatemala, 2008. Monerval, Horizontal Review of Moneyval's third round of mutual evaluation reports. Committee of experts on the evaluation of anti-money laundering measures and the financing of terrorism, Consejo de Europa, Strasbourg, 2010. En https:// rm.coe.int/horizontal-review-of-moneyval-s-third-round-of-mutual-evaluationrepor/168071511d. Consulta: 25.04.2019. 
Montel, J.P., "Sobre la inoponibilidad de la prescripción y de la cosa juzgada en casos de corrupción (pública)", en Gómez Martín, V., Montiel, J.P., y Satzger, H. (eds.), Estrategias penales y procesales de lucha contra la corrupción, Marcial Pons, Barcelona, 2018, pp. 171-194

Muñoz Conde, F., Derecho Penal. Parte Especial, 20ª ed., Tirant Lo Blanch, Valencia, 2015. Muñoz Conde, F., y García Arán, M., Derecho penal. Parte general, ga Ed., Tirant Lo Blanch, Valencia, 2015.

Neira Pena, A. M., “Colaboración público-privada como estrategia para combatir la corrupción: el sistema de responsabilidad penal de las personas jurídicas y los programas de prevención delictiva", en Puente Aba, L.M., (dir.), La proyección de la corrupción en el ámbito penal: análisis de una realidad transversal, Comares, granada, 2017, pp. 93-127.

Nieto Martín, A., "De la ética pública al public compliance: sobre la prevención de la corrupción en las administraciones públicas", en Nieto Martín, A., y Maroto Calatayud, M., (dir.), Public compliance. Prevención de la corrupción en administraciones públicas y partidos políticos, Universidad de Castilla-La Mancha, Cuenca, 2014, pp. 17-42.

Pérez Cepeda, A.I., y Benito Sánchez, D., "La política criminal internacional contra la corrupción", en Berdugo Gómez de la Torre, l., y Liberatore Bechara, A.E., (coord.), Estudios sobre la corrupción. Una reflexión hispano-brasileña, Centro de Estudios Brasileños-Universidad de Salamanca, Salamanca, 2013, pp. 13-55.

Ramírez Barbosa, P.A., "La ley contra las prácticas corruptas en el extranjero. La FCPA de Estados Unidos: "Compliance", extraterritorialidad y responsabilidad de la persona jurídica. Reflexiones acerca del caso Odebrecht", en Ramírez Barbosa, P.A., (dir.), Desafíos del derecho penal en la sociedad del siglo xxi. Libro homenaje a Ignacio Berdugo Gómez de la Torre, Temis, Bogotá, 2018, pp. 3-44.

RANDSTAD, informe anual sobre la flexibilidad laboral y el empleo. 2014. En http://www. randstad.es/tendencias360/informe-flexibilidad-en-el-trabajo-randstad-2014 Consulta: 25.04.2019.

Reátegui SÁnchez, J., "Los delitos de corrupción de funcionario y criminalidad organizada", en Revista de Derecho penal. Delitos contra la administración pública-II, Buenos Aires, 2004, pp. 309-352.

Rebollo Vargas, R., y Casas Hervilla, J., "Reflexiones, problemas y propuestas para la investigación de la delincuencia económica", en Revista General de Derecho Penal, Madrid, 2013 (19), pp. 1-31. 
Rodríguez Moro, L., "Análisis normativo y jurisprudencial de los delitos de tráfico de influencias de los arts. 428 y 429 del Código Penal. Especial referencia a la dificultad de prueba", en Puente Aba, L. M., (dir.), Corrupción y fraudes a consumidores: perspectivas y casos actuales, (Comares, Granada 2016, pp. 173-191.

Rolg TorRes, M., "El comiso como estrategia frente a la corrupción en Alemania: interpretación jurisprudencial", en Estudios penales y criminológicos, Santiago de Compostela, 2018 (XXXVIII extr.), pp. 547-604. En http://www.usc.es/revistas/ index.php/epc/article/view/4473. Consulta: 25.04.2019.

Roma Valdés, A., "La persecución de los delitos de corrupción. Las dificultades de la cooperación internacional en los paraísos fiscales", en Puente Aba, L.M., (dir.), La proyección de la corrupción en el ámbito penal: análisis de una realidad transversal, Comares, Granada, 2017, pp. 41-60.

Rotsch, T., "Corrupción y compliance", en Gómez Martín, V., Montiel, J.P., y Satzger, H. (eds.), Estrategias penales y procesales de lucha contra la corrupción, Marcial Pons, Barcelona, 2018, pp. 227-241.

SÁnchez ZapATA, S.F., "La protección penal del medio ambiente: análisis del art. 338 del CP colombiano sobre minería ilegal", en Actualidad jurídica ambiental, Soria, 2014 (31), pp. 5-28.

Sandhagen, A., "La inversión de la carga de la prueba. A propósito del delito de enriquecimiento ilícito de funcionario público y la aplicación de la teoría de las cargas dinámicas de la prueba", en Revista de derecho penal, 08.04.2017, Buenos Aires. En http://www.pensamientopenal.com.ar/doctrina/47526-inversion-carga-pruebaproposito-del-delito-enriquecimiento-ilicito-funcionario . Consulta: 25.04.2019.

Signor, R., Love, P. E. D., Valim, J. B.C., Raupp, A., y Olatunul, O., "It's not collusion unless you get caught: the case of 'operation car wash' and unearthing of a cartel", en Journal of antitrust enforcement, Oxford, 2019. En https://www.academia. edu/38472281/it_s_not_collusion_unless_you_get_caught_the_case_of_ operation_car_wash_and_unearthing_of_a_cartel. Consulta: 25.04.2019.

Silva SÁnchez, J. M., "Doce tesis sobre el delito de corrupción de funcionarios del art. 286 ter CP español", en Gómez Martín, V., Montiel, J.P., y Satzger, H. (eds.), Estrategias penales y procesales de lucha contra la corrupción, Marcial Pons, Barcelona, 2018, pp.55-66.

Terradillos Basoco, J.M., "Cuatro décadas de política criminal en materia socioeconómica", en Demetrio Crespo, E. (dir.), Crisis financiera y derecho penal económico, Edisofer-Bdef, Madrid, 2014, pp. 45-78. 
Terradilos Basoco, J.M., "Corrupción, globalización y derecho penal económico”, en Demetrio Crespo, E., y González Cuellar Serrano, N. (dir.), Halcones y palomas. Corrupción y delincuencia económica, Castillo De Luna. Ediciones Jurídicas, Madrid, 2015, pp. 15-51.

Terradilos Basoco, J.M., "Mercado y administración pública (criminalidad económica y corrupción política", en Medina Cuenca, A., (coord.), El derecho penal en tiempos de cambios. Libro homenaje al profesor Luis Fernando Niño, Unijuris, La Habana, 2016, pp. 144-176.

Terradillos Basoco, J.M., "Penas privativas de otros derechos. Penas accesorias. Pena de multa", en Berdugo Gómez de la Torre et alii, Curso de derecho penal. Parte general, $3^{\mathrm{a}}$ ed., Experiencia, Barcelona, 2016, pp. 477-497.

Terradillos Basoco, J.M., "Corrupción política: consideraciones político-criminales", en Revista electrónica de estudios penales y de la seguridad, San José (Costa Rica), 2017 (1), pp. 1-31. En https://www.ejc-reeps.com/ . Consulta: 25.04.2019.

Terradillos Basoco, J.M., "Partidos políticos y corrupción política. Algunas estrategias político-criminales", en Medina Cuenca, A. (coord.), Luces y sombras de la reforma penal y procesal en Iberoamérica. Libro homenaje al profesor Dr. Ignacio F. Benítez Ortúzar, Unijuris, La Habana, 2017, pp. 30-35.

Terradillos Basoco, J.M., y Boza Martínez, D., El derecho penal aplicable a las relaciones laborales. Lecciones., Bomarzo, Albacete, 2017.

ValeiJe Álvarez, I., "Malversación (arts. 432. 433, 434 y 435)”, en González Cussac, J.L., (dir.), Comentarios a la reforma del código penal de 2015, 2ª ed., Tirant Lo Blanch, Valencia, 2015, pp. 1205-1216.

VergottinI, G., "Una road contro la corruzione", en Percorsi constituzionali, Cedam, Padova, 2012 (1/2). En http://magna-carta.it/content/road-map-contro-corruzione. . Consulta: 25.04.2019.

Vicente Giménez, T., y Berzosa Alonso Martínez, C., "El triunfo de las finanzas capitalistas y el deterioro de los derechos sociales y de los derechos ecológicos", en Jueces para la democracia, Madrid, 2014 (80), pp. 12-23.

Viganò, F., "I delitti di corruzione nell'ordinamento italiano: qualche considerazione sulle reforme già fatte, e su quel che resta da fare", en Puente Aba, L.M., (edit.), Economía y derecho penal en Europa: una comparación entre las experiencias italiana y española. Actas del congreso hispano-italiano de derecho penal económico", Universidade da Coruña, A Coruña, 2015, pp. 77-110. 